Article

\title{
Enhancement of Diversity in Production and Application Utilizing Electrolytically Polymerized Rubber Sensors with MCF: 1st Report on Consummate Fabrication Combining Varied Kinds of Constituents with Porous Permeant Stocking-Like Rubber
}

\author{
Kunio Shimada ${ }^{1, * \mathbb{D}}$, Ryo Ikeda ${ }^{2}$, Hiroshige Kikura ${ }^{2}$ and Hideharu Takahashi ${ }^{2}$ \\ 1 Faculty of Symbiotic Systems Sciences, Fukushima University, 1 Kanayagawa, Fukushima 960-1296, Japan \\ 2 Institute of Innovative Research, Tokyo Institute of Technology, 2-12-1 Ookayama, Meguro-ku, \\ Tokyo 152-8550, Japan; ikeda.r.ah@m.titech.ac.jp (R.I.); kikura@lane.iir.titech.ac.jp (H.K.); \\ htakahashi@lane.iir.titech.ac.jp (H.T.) \\ * Correspondence: shimadakun@sss.fukushima-u.ac.jp; Tel.: +81-24-548-5214
}

Received: 17 July 2020; Accepted: 29 July 2020; Published: 19 August 2020

check for updates

\begin{abstract}
To satisfy the requirement of haptic sensibility in rubber such as in the proposed hybrid skin (H-Skin), the authors have demonstrated a new method for solidifying rubber using electrolytic polymerization together with configured magnetic clusters of magnetic compound fluid (MCF) incorporated into the rubber by the application of a magnetic field. However, the rubber and magnetic fluid (MF) involved in the MCF rubber were water-soluble. In addition, the authors have demonstrated the practicability of using electrolytic polymerization with an emulsifier, polyvinyl alcohol (PVA), in which natural rubber (NR) or chloroprene rubber (CR) and silicone rubber (Q) can be mixed as water-soluble and water-insoluble rubbers, respectively. In this study, to enhance production, the feasibility of solidifying rubber by electrolytic polymerization is verified using varied water-insoluble rubber, varied water-insoluble $\mathrm{MF}$, and varied surfactants to aid emulsion polymerization, except in the case of other kinds of rubber and MF which have been demonstrated until recent by the authors. Based on these diverse constituents, the authors propose a consummate fabrication process for multi-layered MCF rubber, which involves porous stocking-like rubber that can be permeated by any liquid. The investigation of this application is presented in the sequential second report.
\end{abstract}

Keywords: sensor; diene rubber; surfactant; porous; permeation; electrolytic polymerization; magnetic compound fluid (MCF); hybrid skin (H-skin)

\section{Introduction}

Sensors require haptic sensibility in rubber under normal or shear motions, including sensibilities to temperature or photoreaction. The haptic sensibility that is provided to robots predominantly corresponds with sensing normal or shear forces and temperature [1-3]. These sensibilities are related to the five types of touch sensations in the human skin: tactile, baresthesia, algometry, warm, and cold [4]. When sensibility is incorporated into the skin of a robot, the material that is feasible to the outer artificial skin installed on it is termed sensitive skin, smart skin, or electronic skin (E-Skin) [5]. As an alternative artificial skin, the authors have also proposed a hybrid skin (H-Skin) with multiple functionalities, including flexibility, thermo-sensitivity, photovoltaics, and ability to sense modalities to its forces [6-8]. 
H-skin is produced by a new method using solidified rubber by electrolytic polymerization, together with the configuration of magnetic clusters of metal particles integrated into the rubber by the application of a magnetic field [9-11]. The resulting material is named magnetic compound fluid (MCF) rubber. This novel solidification method differs from the conventional vulcanization technique, where sulfur is used on the field for the normal production of solid rubber [12]. However, in the case of $\mathrm{MCF}$, it possesses nm-ordered magnetite $\left(\mathrm{Fe}_{3} \mathrm{O}_{4}\right)$ particles that are obtained using a magnetic fluid (MF) during compounding, and $\mu \mathrm{m}$-ordered metal particles, such as Fe and Ni. Because it is an effective magnetic-responsive intelligent fluid, MCF has been proposed as an alternative in many engineering applications, such as dampers and polishing machines [13]. By applying a magnetic field on the MCF rubber during electrolytic polymerization, the magnetic particles of MCF are fabricated as heterostructures like in many needle-like clusters so that the electric and photovoltaic properties of MCF rubber are enhanced, as well as its mechanical and electrical properties becoming anisotropic. Furthermore, to fabricate an MCF rubber sensor, a novel adhesion technique between rubber and metal has been proposed with hydrate-containing fabricated metallic or non-metallic elements under electrolytic polymerization to adhere plate- or wire-type electrodes to the rubber without the occurrence of detachment caused by large tension [14]. On one hand, the rubber that has been provided with electrolytic polymerization is water-soluble, which includes natural rubber (NR) and chloroprene rubber (CR) categorized as diene rubber. On the other hand, the water-insoluble rubber, silicone rubber (Q), can be electrolytically polymerized to be solidified together with water-soluble rubber such as NR or CR by mixing polyvinyl alcohol (PVA) as a surfactant or an emulsifier [15].

However, the authors have dealt with the combination of Q, NR, CR, PVA, and water-base MF alone until recent [15]. Other diverse combinations must be managed for example, the combination of water-insoluble rubber and water-insoluble MF, water-soluble rubber and water-insoluble liquid, that of other emulsifiers, and so on, which are not elucidated yet. It is critical to validate the practicability of electrolytic polymerization for the solidification of rubber with various combinations because the production of solidified rubber is convenient, whichever diverse kinds of rubber and MF are used. From point of view of other researches to have been conducted on so far, it is significant to develop the emergence of rubber blends by mixing two or more than polymers together in the field of polymer and rubber sciences so that many investigations have been conducted on, for example, by combining water-soluble and insoluble rubbers [16]. Carbon black or nanotube as well as ethylene-propylene-diene rubber (EPDM) has been often used, and the former was for its reinforcement of the rubber [17]. The method how to solidify these rubbers was the vulcanization with sulfur. As for the combination of $\mathrm{MF}$ and rubber, $\mathrm{Q}$ has been often used [18,19]. On these investigations, the problem of the combination of rubber and MF as well as the combination of water-soluble and insoluble rubbers, has not been focused on vulcanization. Their primary purposes were to advance highly the functional properties, mechanical or electrical properties. Therefore, it is meaningful to verify and construct the mechanism of the combination of the diverse kinds of rubber and MF in our present study. In addition, little attention to the investigation of the combination of varied emulsifier with the rubber has been given to the point. PVA has the role played by the emulsion polymerization so that PVA is significant in the electrolytic polymerization of combined diene and non-diene rubbers. Conventionally has MF the surfactant of oleic acid that has also the role played by the emulsion polymerization. It remains an unsettled question how the emulsifier or surfactant combines with the rubber. Moreover, it is important to address the fabrication of the MCF rubber sensor with various combinations of rubber, MF and emulsifier. Because the fabrication of the MCF rubber sensor by the combination of $Q, N R, C R$, PVA, and water-base MF alone has been proposed [14].

Regarding the fabrication, if the MCF rubber initially involves a liquid-type dopant, the MCF rubber sensor can have a variety of properties, which are mainly divided into three types by the kinds of dopants: conductive, piezo, and battery types. The solid type dopant only needs to be mixed; however, the feasibility of involving the liquid-type dopant in the MCF rubber might be realized by the permeation of liquids. In order to do that, we might utilize the technique for making rubber 
porous. From point of view of other studies to have been conducted on so far, various ideas have been proposed. For example, $\mathrm{NaCl}$ particles that are initially mixed in $\mathrm{Q}$ and vulcanized are washed and removed by water to obtain porosity [20]. A porous structure is also formed with composites blended by rubber and cement, which are mixed with asphalt and rubber for concrete pavement; however, this rubber is much stiffer than the proposed MCF rubber [21]. Additionally, a porous material can be fabricated by mixing ammonia stabilizer in NR with a carbon nanotube fiber and by the evaporation of the stabilizer when heat is applied [22]. The porous material containing cellulose fiber is mixed with styrene-butadiene rubber (SBR) and asphalt, and porosity can be obtained by evaporating water in the mixture [23]. Porous rubber has been predominantly used for the permeability of gas and liquid or composites with concrete or asphalt. However, our proposing idea in the present study of electrolytically polymerized porous and permeable rubber has not yet been proposed. We must address the fabrication of the MCF rubber sensor with utilizing the porous MCF rubber involving a liquid-type dopant. The production of the porous rubber and the permeation of dopants into the rubber are other typical subjects in the present study.

In this study, the authors investigate the viability of: (1) electrolytic polymerization technique for the solidification of diverse rubbers with diverse combinations of various rubbers and MFs using various emulsifiers; (2) the fabrication process of the MCF rubber sensor with their combinations and the MCF rubber permeated by liquids, which are the novelty of the current work. In addition, as the technique and process are enhanced for diverse applications, the authors try to apply the fabricated MCF rubber sensor to fields related to normal or shear forces and temperature, which is presented in the second report [24].

\section{Electrolytic Polymerization}

\subsection{Rubber}

Rubber is divided into diene and non-diene rubbers or natural and synthetic rubbers and categorized as shown in Figure A1 (Appendix A). For diene rubber, the latex in a liquid state as in NR, $\mathrm{CR}$, isoprene rubber (IR), and butadiene rubber (BR) can be solidified by electrolytic polymerization. This can be achieved because diene rubber contains $C=C$ bonds and water, which has been elucidated in the previous research [9-12]. These latexes are electrolytes that contain enough water to be provided by electrolysis. Nitrile rubber (NBR) and SBR, however, cannot be provided with electrolytic polymerization and cannot be solidified because they have potentially high viscosity. In contrast, non-diene rubber contains $\mathrm{C}-\mathrm{C}$ bonds such that electrolytic polymerization cannot be utilized. However, by utilizing PVA and mixing water-soluble diene-rubber such as NR-latex or CR-latex, the silicone oil in a liquid state $(\mathrm{Q})$ can be solidified by electrolytic polymerization. Basically, $\mathrm{Q}$ is structured as the basis of dimethylpolysiloxane (PDMS) and PVA is an emulsifier, allowing PDMS and PVA to be combined by emulsion polymerization. The anionized hydroxy group of PVA and NR-latex or CR-latex are bonded by hydrogen boding. This mechanism has been elucidated in previous research [15]. However, when the water-soluble diene-rubber rubber is not mixed with water-insoluble non-diene rubber, electrolytic polymerization might become possible, provided the non-diene rubber contains a fair portion of $C=C$ bonds in its molecular structure and liquid state. As another way of validating electrolytic polymerization using PVA and mixing NR-latex or CR-latex except for Q, the electrolytic polymerization of urethane rubber $(\mathrm{U})$ is demonstrated in this study.

The U used in this study was polyurethane (C7 with hardness measured by C-type durometer, hardness meter (Kobunshi Keiki, Co., Ltd., Kyoto, Japan), Exseal Co. Ltd., Gifu, Japan). It was emulsified by PVA, with either NR-latex, CR-latex, or their composite latexes bonded with the anionized hydroxy group of the PVA by hydrogen boding. The MCF rubber liquid consisted of $3 \mathrm{~g} \mathrm{Ni}$ powder with particles in the order of microns and bumps on the surface (No. 123 by Yamaishi Co. Ltd., Noda, Japan), $3 \mathrm{~g}$ PVA, $0.75 \mathrm{~g}$ water-based MF with $40 \mathrm{wt} \% \mathrm{Fe}_{3} \mathrm{O}_{4}$ (W-40, Ichinen-Chemicals Co., Ltd., Shibaura, Japan), 3 g CR-latex (671A, Showa Denko Co. Ltd., Tokyo, Japan), 0.5 g TiO 2 (Anatase type, 
Fujifilm Wako Pure Chemical Co., Ltd., Osaka, Japan), 3 g NR-latex (without sulfur, Ulacol, Rejitex Co. Ltd., Atsugi, Japan), or S-500 (NR-latex with sulfur, Rejitex Co. Ltd., Atsugi, Japan). U and PVA must be mixed in an advance combination as in Q [15] because if $U$ is combined with a single NR-latex or CR-latex, or their mixture, they are solidified during stirring. They must also be stirred under cooling conditions with ice water. Subsequently, the MCF rubber liquid was electrolytically polymerized, where a static magnetic field of $312 \mathrm{mT}$ was applied to a pair of stainless electrodes with a $1 \mathrm{~mm}$ gap using permanent magnets as paired opposites via the application of a constant electric field at $20 \mathrm{~V}$ and $2.7 \mathrm{~A}$, for $5 \mathrm{~min}$.

Incidentally, as provided throughout the experiment of this study, the magnetic field strength and electric current can be determined by optimum magnitude, as has been presented in the previous studies [15]. It can be measured with the Gauss meter probe, which is a traditional instrument for magnetic field measurement. Based on many experiments, $312 \mathrm{mT}$ was confirmed to be the optimal magnetic field strength in the production method proposed in this study. With a gap of $1 \mathrm{~mm}$ between electrodes, permanent magnets were paired opposites via a constant electric field at $2.7 \mathrm{~A}$ with a voltage range of 6-30 V, for 5-30 min. Therefore, $312 \mathrm{mT}$ and $2.7 \mathrm{~A}$ were used during this study.

Figure 1 shows images of liquid MCF rubber before electrolytic polymerization and electrolytically polymerized MCF rubber. As shown in Figure 1a, the combination of diene and non-diene rubber latexes with MCF results in a highly uniform dispersion. As seen in Figure 1f, the rubber molecules exhibit mutual conjuncts to be crosslinked.

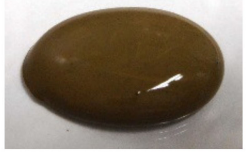

(a)

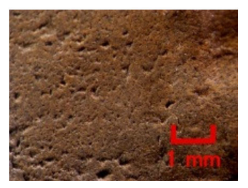

(e)

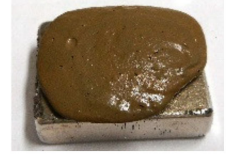

(b)

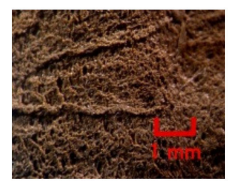

(f)

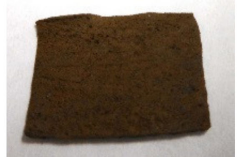

(c)

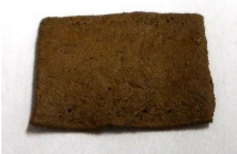

(d)

Figure 1. Images of liquid MCF rubber before electrolytic polymerization and electrolytically polymerized MCF rubber containing U: (a) liquid MCF rubber before electrolytic polymerization without a magnetic field; (b) liquid MCF rubber before electrolytic polymerization under a magnetic field; (c) panoramic image of electrolytically polymerized MCF rubber facing anode; (d) panoramic image of electrolytically polymerized MCF rubber facing cathode; (e) microscopic image of electrolytically polymerized MCF rubber facing anode by optical microscope; (f) microscopic image of electrolytically polymerized MCF rubber facing cathode by optical microscope.

The electrical property of the voltage induced inner MCF rubber at compression was measured using the same NFE experimental apparatus as in the previous study [9]. NFE specified that the upper electrode is moved to touch the MCF rubber sensor, which is squeezed between the electrodes, onto the lower one by an actuator at a pressing speed of $10 \mathrm{~mm} / \mathrm{min}$. The normal pressing force was measured by a load cell, which was installed in the actuator. The actuator utilizes the commercial, small-size tensile testing machine (SL-6002, IMADA-SS Co. Ltd., Toyohasi, Japan). The voltage between the electrodes can be measured without installing a power supply. The paired electrodes used had the same $7 \mathrm{~mm} \times 7 \mathrm{~mm}$ square form. The measurement was for induced voltage related to piezo-electricity, which was evaluated as built-in electricity, built-in voltage, and current [25]. The built-in electricity occurred by ionized molecules, particles of rubber latex and oleic acid-coated around $\mathrm{Fe}_{3} \mathrm{O}_{4}$ of $\mathrm{MF}_{\text {, }}$ water, and PVA. They play the role of an acceptor-like p-type semiconductor (corresponding to $\mathrm{A}^{-}$ as presented in the previous study $[6,12]$ ), or a donor-like n-type semiconductor (corresponding to 
$\left.\mathrm{D}^{+}[6,12]\right)$. Figure 2 shows that the induced voltage applies pressure repeatedly. The resulting MCF rubber just after production contains induced voltage which is independent of pressure, although, after some lapses, become a piezo-element that depends on pressure. At any rate, the electrolytic polymerization technique that utilizes PVA and mixing water-soluble diene rubber such as NR-latex or CR-latex with non-diene rubber is feasible.

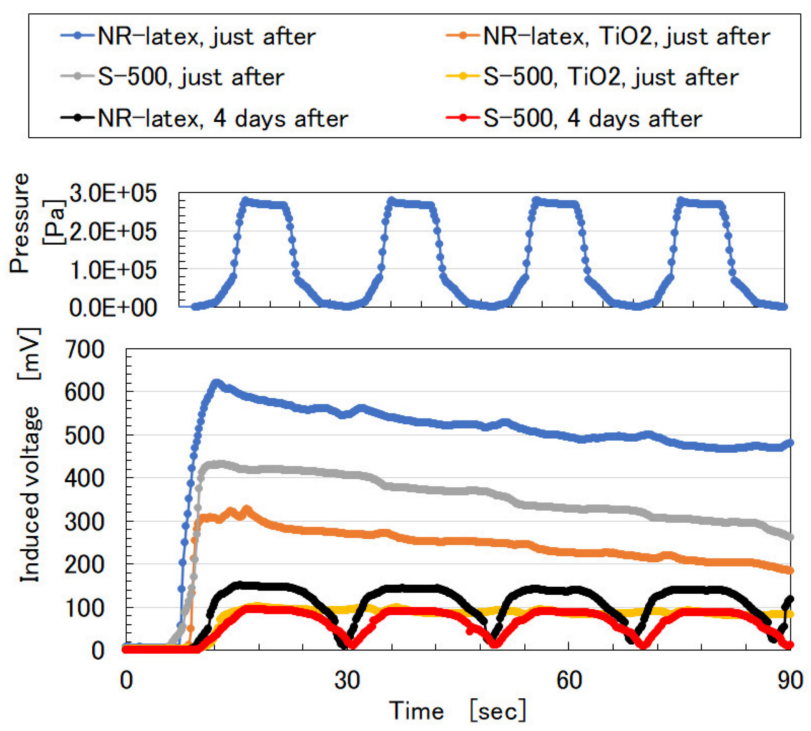

Figure 2. Induced voltage of MCF rubber with $U$ to repeat pressure application: either NR-latex or S-500 is compounded; $\mathrm{TiO}_{2}$ presents the use of $\mathrm{TiO}_{2}$; "just after" means the measurement just after the production; " 4 days after" means the measurement from the production after 4 days.

\subsection{Water-Insoluble Liquid and MF}

The roles that NR-latex or CR-latex and Q or U play can be combined through the medium of emulsion polymerization with a PVA-enabled non-conductive rubber such as non-diene rubber to be solidified by the application of an electric field. This role connotes the possibility of mixing water-insoluble liquid and water as shown in Figure $3 a, c, e$, and the practicability of mixing water-insoluble MF and water-base MF as shown in Figure 4a,c. Various kinds of MFs exist, and in this study, the authors deal with a well-known base MF and its solvent as a water-insoluble liquid. As shown in Figure 3, the liquid has $3 \mathrm{~g}$ PVA, $0.75 \mathrm{~g}$ water, $0.75 \mathrm{~g} \mathrm{Fe}_{3} \mathrm{O}_{4}$ powder (Fujifilm Wako Pure Chemical Co., Ltd., Osaka, Japan), $3 \mathrm{~g}$ Ni, and $0.75 \mathrm{~g}$ water-insoluble liquid (kerosene, alkyl naphthalene, paraffin). As represented in Figure 4, the liquid has $3 \mathrm{~g}$ PVA, $0.75 \mathrm{~g} \mathrm{MF}$ (W40), $3 \mathrm{~g} \mathrm{Ni}$, and $0.75 \mathrm{~g}$ water-insoluble MF (kerosene base MF (MSGS60, Ferrotec Co., Ltd., Tokyo, Japan), and alkyl naphthalene base MF (A500, Sigma Hi-Chemical Co., Ltd., Kanagawa, Japan)). The mixing process is presented in Figure 5. Consequently, via an emulsion polymerization medium by PVA, water-insoluble liquid or water-insoluble MF can be combined with an inner diene type MCF rubber, such as a water-soluble type MCF rubber. In this mechanism, the water-insoluble liquid and PVA can be combined by the emulsion polymerization of PVA, and the anionized hydroxy group of PVA and water are bonded by hydrogen boding. However, regarding Figure $3 b, d, f$ and Figure $4 b, d$, when a magnetic field is applied, the liquid seems to be divided into magnetic and non-magnetic materials because of the mixed magnetic particles and non-magnetic materials. Under these phenomena, it is strange that the MCF rubber containing water-insoluble liquid or MF possessed electrical properties and was electrolytically polymerized. This anomaly is indicated in sequential figures. 


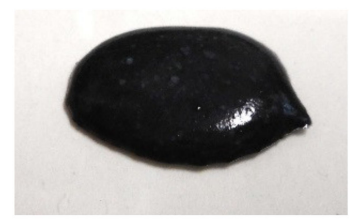

(a)

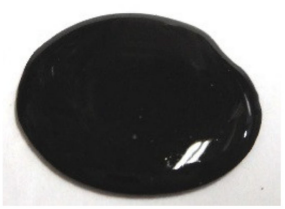

(e)

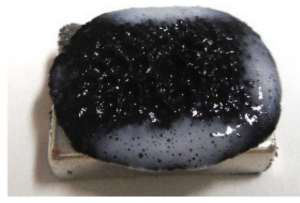

(b)

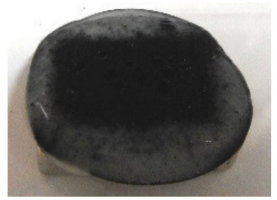

$(\mathbf{f})$

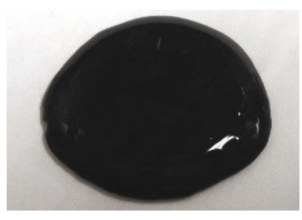

(c)

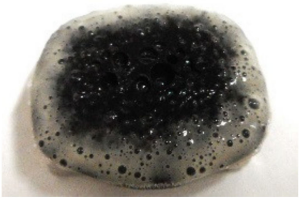

(d)

Figure 3. Images of liquid mixed with water-insoluble liquid and water: (a) kerosene mixed without a magnetic field; (b) kerosene mixed under a magnetic field; (c) alkyl naphthalene mixed without a magnetic field; (d) alkyl naphthalene mixed under a magnetic field; (e) paraffin mixed without a magnetic field; (f) paraffin mixed under a magnetic field.

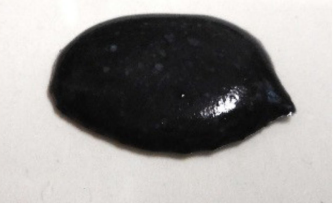

(a)

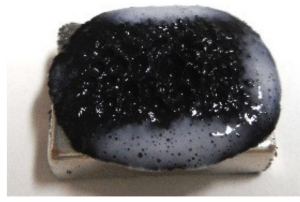

(b)

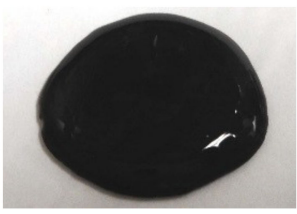

(c)

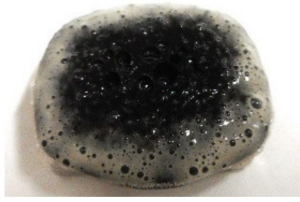

(d)

Figure 4. Images of liquid mixed water-insoluble MF and water-based MF: (a) kerosene-based MF mixed without a magnetic field; (b) kerosene-based MF mixed under a magnetic field; (c) alkyl naphthalene-based MF mixed without a magnetic field; (d) alkyl naphthalene-based MF mixed under a magnetic field.

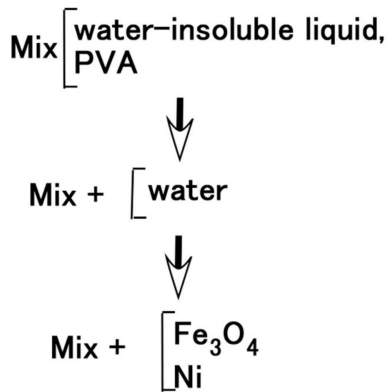

(a)

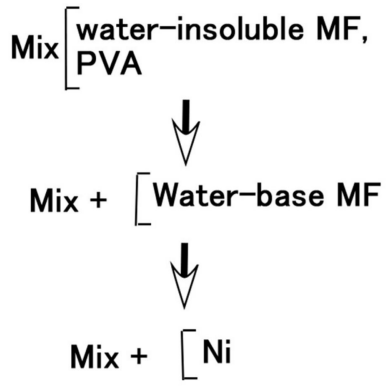

(b)

Figure 5. Mixing process; (a) for Figure 3; (b) for Figure 4.

In the case without the application of a magnetic field, via an emulsion polymerization medium by PVA, water-insoluble liquid or water-insoluble MF can be combined with an inner diene type MCF rubber, such as a water-soluble type MCF rubber. As regards the former, the combined MCF rubber liquid with or without a magnetic field and the electrolytically polymerized MCF rubber, are shown in Figure 6. In the case of the latter, it is represented in Figure 7 while the method of mixing is shown in Figure 8. In Figure 6, the MCF rubber liquid consisted of $3 \mathrm{~g}$ Ni, $3 \mathrm{~g}$ PVA, $3 \mathrm{~g}$ 671A, $3 \mathrm{~g}$ NR-latex, 0.75 $\mathrm{g} \mathrm{Fe}_{3} \mathrm{O}_{4}$, and $0.75 \mathrm{~g}$ water-insoluble liquid (kerosene, alkyl naphthalene, and paraffin). In Figure 7 , the MCF rubber liquid consisted of $3 \mathrm{~g}$ Ni, $3 \mathrm{~g}$ PVA, $3 \mathrm{~g}$ 671A, $3 \mathrm{~g}$ NR-latex, $0.75 \mathrm{~g}$ water-insoluble MF (MSGS60, A500, another kerosene base MF (HC50, Ichinen-Chemicals Co., Ltd.), and diesters 
base MF (DS50, Sigma Hi-Chemical Co., Ltd.). With a $1 \mathrm{~mm}$ gap between the electrodes, a $312 \mathrm{mT}$ magnetic field, and an electric current field at $20 \mathrm{~V}$ and $2.7 \mathrm{~A}$ were applied for $5 \mathrm{~min}$. In this mechanism, water-insoluble liquid (or MF) and PVA can be combined by the emulsion polymerization of PVA, and the anionized hydroxy group of PVA and NR-latex (or CR-latex) are bonded by hydrogen boding.

When a magnetic field is applied before electrolytic polymerization, the MCF rubber liquids, as shown in Figure $6 b, h, n$ and Figure $7 b, h, n, t$, are less clearly divided than those in the cases without using water-soluble rubber, as shown in Figure $3 b, d, f$ and Figure $4 b, d$. In contrast, when electric polymerization is applied under a magnetic field, the MCF rubber is not distinctively divided into two, areas such as magnetic and non-magnetic materials.

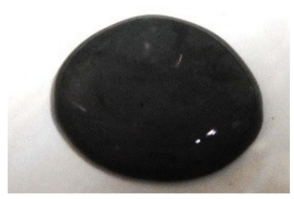

(a)

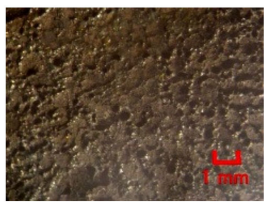

(e)

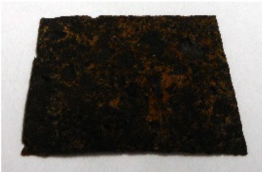

(i)

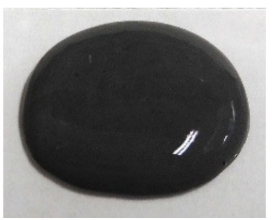

(m)

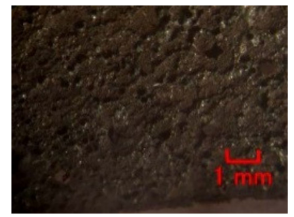

(q)

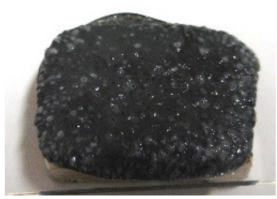

(b)

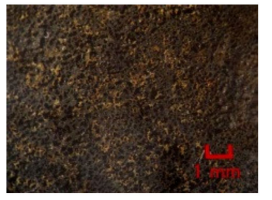

(f)

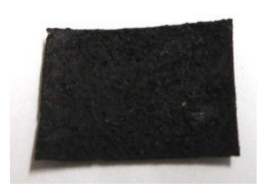

(j)

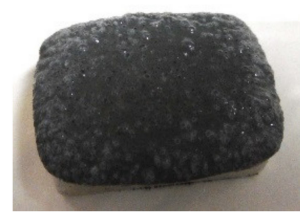

(n)

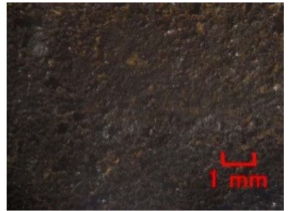

(r)

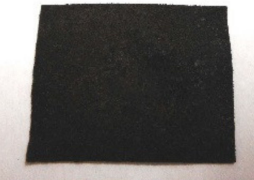

(c)

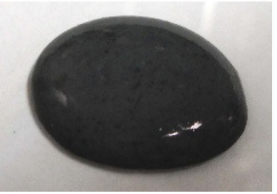

(g)

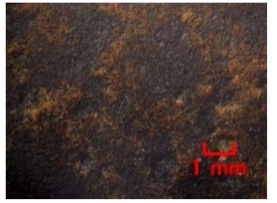

(k)

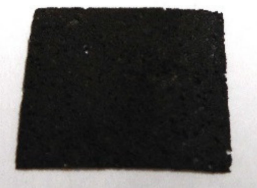

(o)

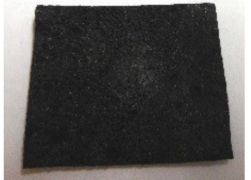

(d)

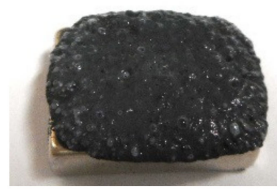

(h)

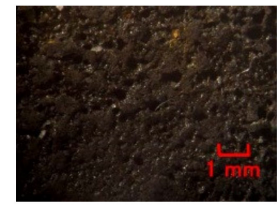

(I)

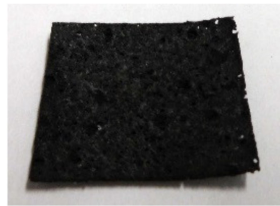

(p)

Figure 6. Images of liquid before electrolytic polymerization and mixing electrolytically polymerized rubber with water-insoluble liquid: (a-f) kerosene; (g-l) alkyl naphthalene; (m-r) paraffin; $(\mathbf{a}, \mathbf{g}, \mathbf{m})$ liquid before electrolytic polymerization without magnetic field; $(\mathbf{b}, \mathbf{h}, \mathbf{n})$ liquid before electrolytic polymerization under magnetic field; $(\mathbf{c}, \mathbf{i}, \mathbf{o})$ panoramic image of electrolytically polymerized rubber facing anode; $(\mathbf{d}, \mathbf{j}, \mathbf{p})$ panoramic image of electrolytically polymerized rubber facing cathode; $(\mathbf{e}, \mathbf{k}, \mathbf{q})$ microscopic image of electrolytically polymerized rubber facing anode by optical microscope; $(\mathbf{f}, \mathbf{l}, \mathbf{r})$ microscopic image of electrolytically polymerized rubber facing cathode by optical microscope. 


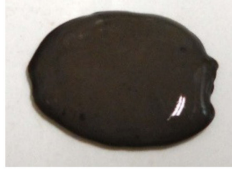

(a)

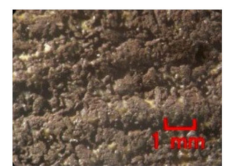

(e)

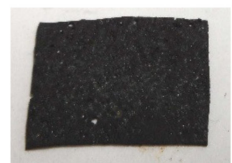

(i)

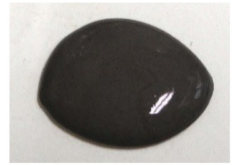

(m)

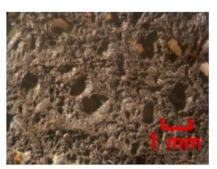

(q)

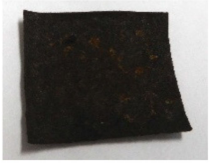

(u)

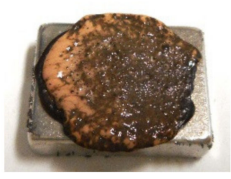

(b)

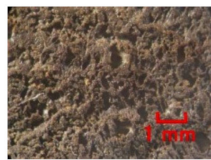

(f)

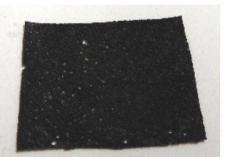

(j)

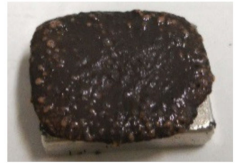

(n)

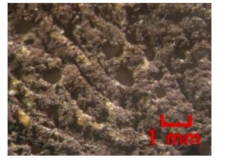

(r)

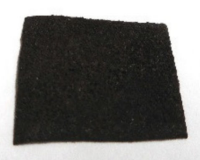

(v)

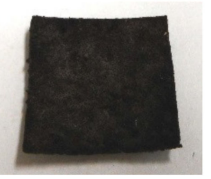

(c)

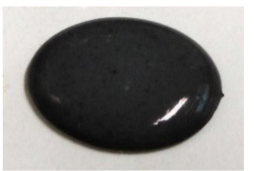

(g)

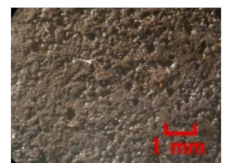

(k)

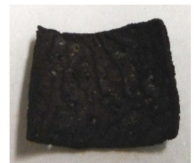

(o)

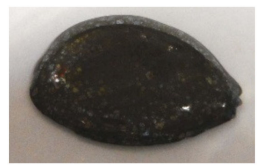

(s)

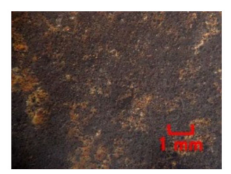

(w)

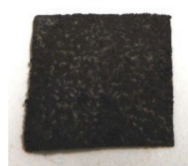

(d)

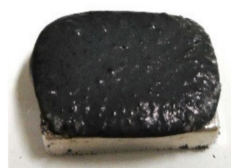

(h)

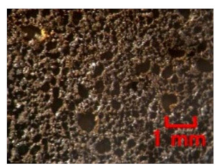

(I)

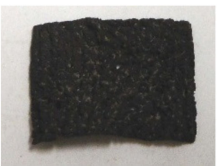

(p)

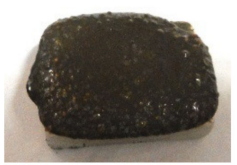

(t)

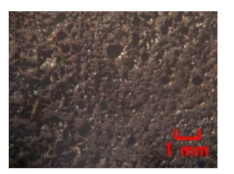

(x)

Figure 7. Images of liquid before electrolytic polymerization and mixing electrolytically polymerized rubber with water-insoluble MF: (a-f) MSGS60; (g-1) A500; (m-r) HC50; (s-x) DS50; (a,g,m,s) liquid before electrolytic polymerization without magnetic field; $(\mathbf{b}, \mathbf{h}, \mathbf{n}, \mathbf{t})$ liquid before electrolytic polymerization under magnetic field; $(\mathbf{c}, \mathbf{i}, \mathbf{o}, \mathbf{u})$ panoramic image of electrolytically polymerized rubber facing anode; $(\mathbf{d}, \mathbf{j}, \mathbf{p}, \mathbf{v})$ panoramic image of electrolytically polymerized rubber facing cathode; $(\mathbf{e}, \mathbf{k}, \mathbf{q}, \mathbf{w})$ microscopic image of electrolytically polymerized rubber facing anode by optical microscope; $(\mathbf{f}, \mathbf{l}, \mathbf{r}, \mathbf{x})$ microscopic image of electrolytically polymerized rubber facing cathode by optical microscope.

As for the MCF rubbers of Figures 6 and 7, the pressure was repeatedly applied by the induced voltage, as shown in Figures 9a and 10a. Aside from the induced voltage causing piezo-electricity, there was another effect on a piezo-element, piezo-resistivity [25]. A piezo-resistive element requires the application of voltage by a power supply, thus producing the changes in resistivity experienced by the piezo-element. This element is essentially an electric conductor that allows electrons to percolate through the material, and the mechanism of this electric conductivity is explained mainly by percolation or tunnel theory [6]. By applying the voltage to the MCF rubber, the authors measured the electrical current passing through the MCF rubber at compression using the same NFE experimental apparatus as in the measurement of piezo-electricity, as shown in Figures $9 \mathrm{~b}$ and $10 \mathrm{~b}$. The MCF rubber induced voltage and electric current, which are dependent on pressure, and the response to pressure is different depending on the kind of water-insoluble liquid and MF. In any case, the diene type MCF rubber that 
is mixed by water-insoluble liquid or water-insoluble MF, which uses the emulsion polymerization of PVA, has a feasibility of haptic sensing.

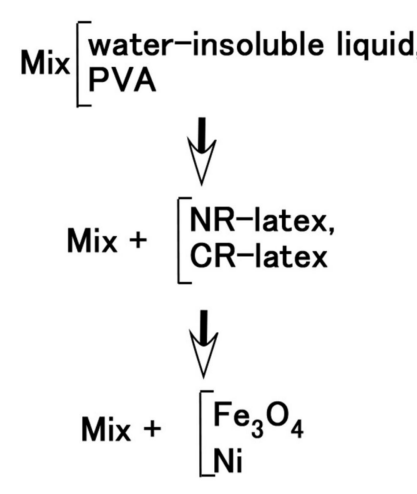

(a)

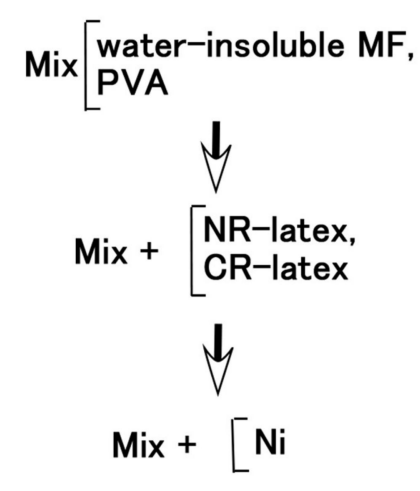

(b)

Figure 8. Mixing process for: (a) Figure 6; (b) Figure 7.

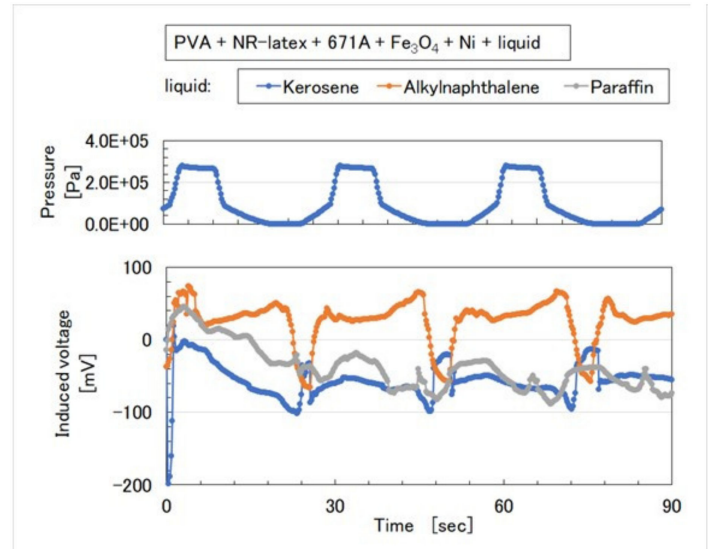

(a)

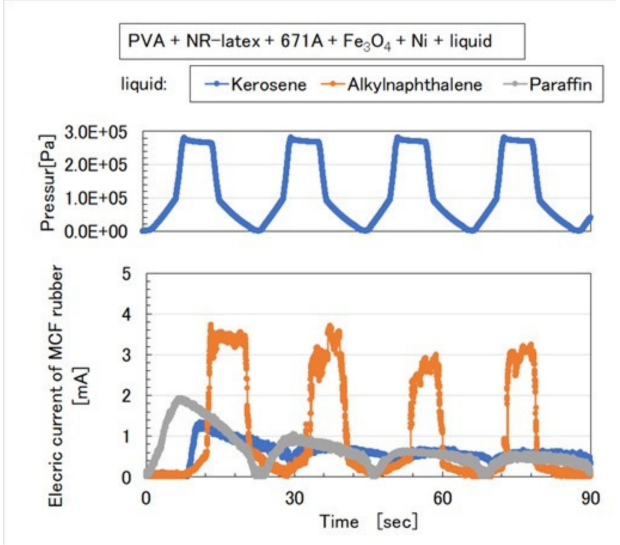

(b)

Figure 9. Induced voltage and electric current as piezo-resistivity of MCF rubber with water-insoluble liquid to repeat pressure application in Figure 6: (a) piezo-electricity; (b) piezo-resistivity.

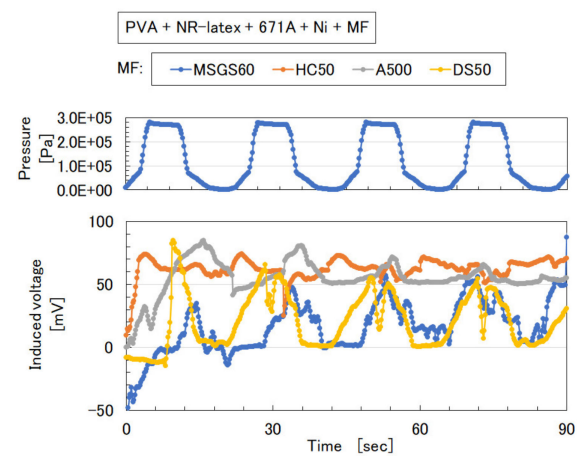

(a)

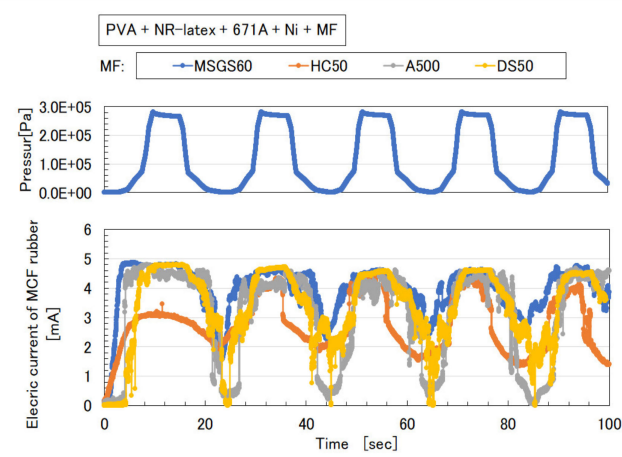

(b)

Figure 10. Induced voltage and electric current as piezo-resistivity of MCF rubber with water-insoluble MF to repeat pressure application in Figure 7: (a) piezo-electricity; (b) piezo-resistivity. 


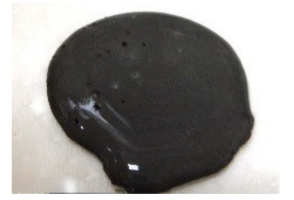

(a)

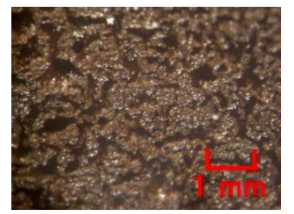

(e)

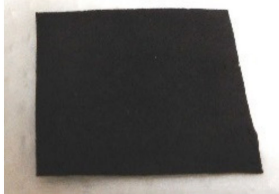

(i)

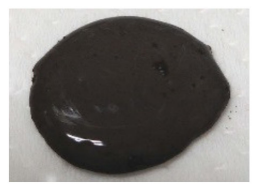

(m)

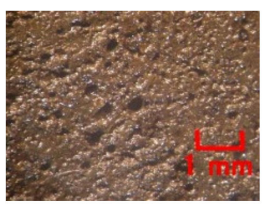

(q)

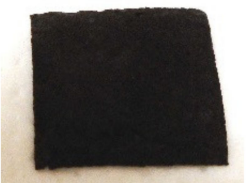

(u)

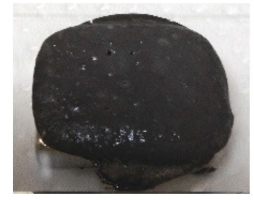

(b)

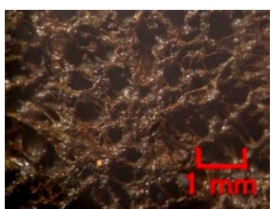

(f)

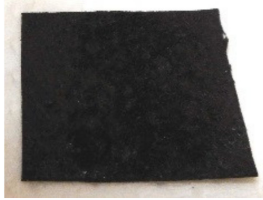

(j)

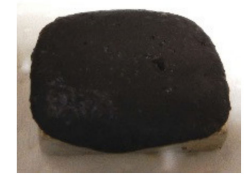

(n)

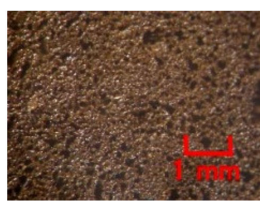

(r)

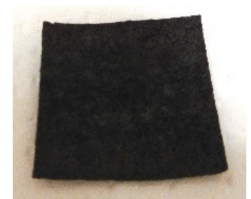

(v)

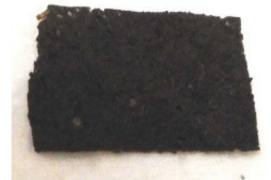

(c)

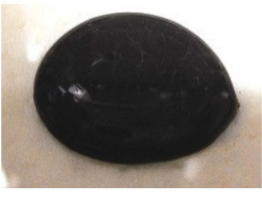

(g)

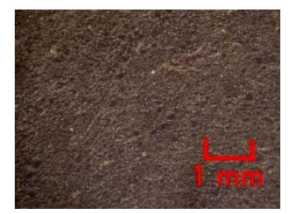

(k)

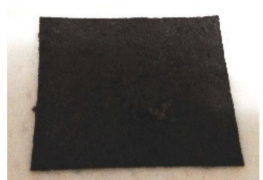

(o)

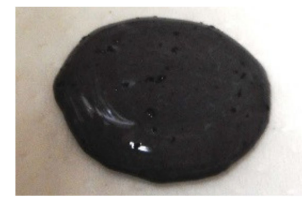

(s)

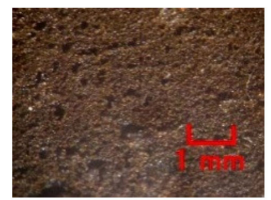

(w)

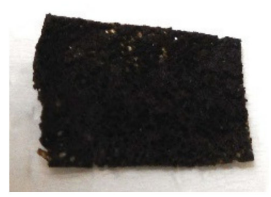

(d)

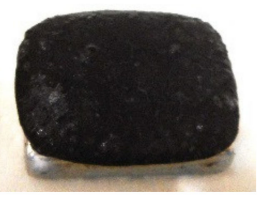

(h)

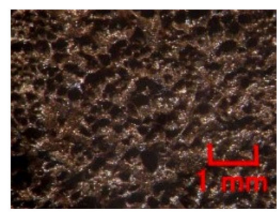

(I)

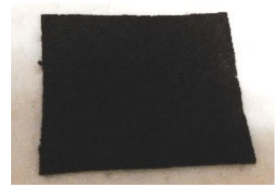

(p)

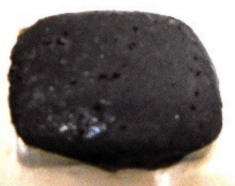

(t)

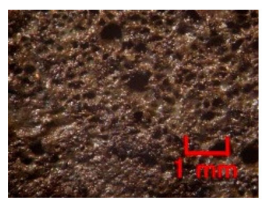

(x)

Figure 11. Images of liquid before electrolytic polymerization and electrolytically polymerized rubber mixed with KF96 and water-insoluble MF: (a-f) MSGS60; (g-1) A500; (m-r) HC50; (s-x) DS50; (a,g,m,s) liquid before electrolytic polymerization without magnetic field; $(\mathbf{b}, \mathbf{h}, \mathbf{n}, \mathbf{t})$ liquid before electrolytic polymerization under magnetic field; $(\mathbf{c}, \mathbf{i}, \mathbf{o}, \mathbf{u})$ panoramic image of electrolytically polymerized rubber facing anode; $(\mathbf{d}, \mathbf{j}, \mathbf{p}, \mathbf{v})$ panoramic image of electrolytically polymerized rubber facing cathode; $(\mathbf{e}, \mathbf{k}, \mathbf{q}, \mathbf{w})$ microscopic image of electrolytically polymerized rubber facing anode by optical microscope; $(\mathbf{f}, \mathbf{l}, \mathbf{r}, \mathbf{x})$ microscopic image of electrolytically polymerized rubber facing cathode by optical microscope.

Next, the authors investigated the possibility of haptic sensing in the case of non-diene type MCF rubber, such as water-insoluble type MCF rubber, which is mixed with a water-insoluble material (MF and liquid) through the medium of emulsion polymerization by PVA and by mixing water-soluble rubber, such as NR-latex or CR-latex. When the emulsion polymerization of PVA is used to mix 
MCF rubber with $Q$ and NR-latex or CR-latex, the resulting combination of water-insoluble MF is investigated. In this mechanism, water-insoluble MF and PVA can be combined by the emulsion polymerization of PVA, and the anionized hydroxy group of PVA and NR-latex (or its mixture with CR-latex) are bonded by hydrogen boding. KF96 is processed as Q, which is a pure silicone oil without any silane, such that it cannot be solidified by mixing it with a curing agent. As for Figure 11, the MCF rubber liquid consisted of $3 \mathrm{~g} \mathrm{Ni}, 3 \mathrm{~g}$ PVA, 3 g NR-latex, $3 \mathrm{~g}$ KF96 (1000 cSt, Shin-Etsu Chemical Co. Ltd., Tokyo, Japan), and $0.75 \mathrm{~g}$ water-insoluble MF (NSGS60, A500, HC50, DS50). In the case represented in Figure 12, the MCF rubber liquid consisted of $3 \mathrm{~g} \mathrm{Ni}, 3 \mathrm{~g}$ PVA, $3 \mathrm{~g}$ 671A, $3 \mathrm{~g}$ NR-latex, $3 \mathrm{~g}$ KF96 (1000 cSt), $0.75 \mathrm{~g} \mathrm{MF} \mathrm{(W40),} \mathrm{and} 0.75 \mathrm{~g}$ water-insoluble MF (MSGS60, A500). The method of mixing is presented in Figure 13. A $312 \mathrm{mT}$ magnetic field and an electric field at $20 \mathrm{~V}$ and 2.7 A were applied for 5 min with a $1 \mathrm{~mm}$ gap between the electrodes. When $\mathrm{Q}$ is combined with MCF rubber liquids by applying a magnetic field before electrolytic polymerization, as shown in Figure $11 b, h, n, t$ and Figure $12 b$,h, the resulting combination becomes more uniform than those in the cases without $Q$ such as those in Figure $6 b, h, n$ and Figure $7 b, h, n, t$. Although the surfaces of electrolytically polymerized rubber facing anode seen in Figure 11e,k,q,w and Figure 12e,k are smooth, those facing cathode seen in Figure 11f,l,r, $x$ and Figure 12f,l are rougher than those in the cases without $Q$ such as those in Figure $6 f, 1, r$ and Figure $7 f, 1, r, x$. In the case involving the combination of diene and non-diene rubbers, water-insoluble MF or the compound of water-insoluble and water-based MFs can be mixed so that the MCF rubber can be electrolytically polymerized.

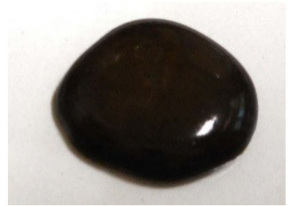

(a)

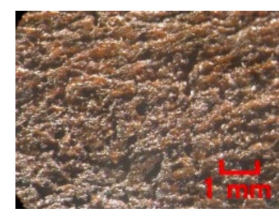

(e)

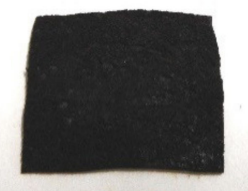

(i)

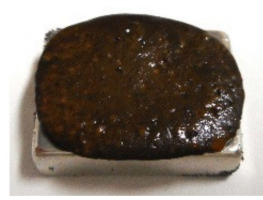

(b)

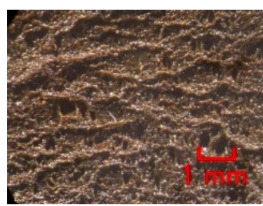

(f)

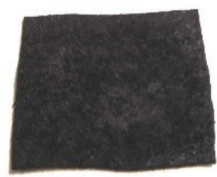

(j)

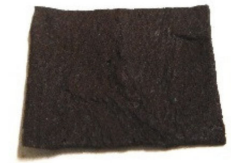

(c)

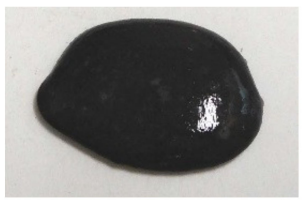

(g)

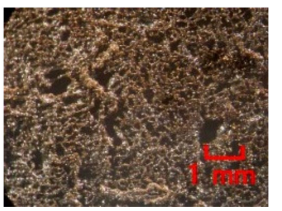

(k)

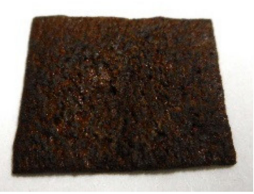

(d)

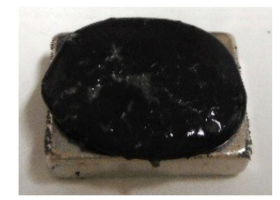

(h)

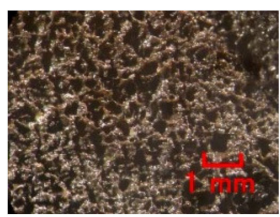

(l)

Figure 12. Images of liquid before electrolytic polymerization and electrolytically polymerized rubber mixed with KF96, W40, water-insoluble MF: (a-f) MSGS60; (g-1) A500; (a,g) liquid before electrolytic polymerization without magnetic field; $(\mathbf{b}, \mathbf{h})$ liquid before electrolytic polymerization under magnetic field; (c,i) panoramic image of electrolytically polymerized rubber facing anode; $(\mathbf{d}, \mathbf{j})$ panoramic image of electrolytically polymerized rubber facing cathode; $(\mathbf{e}, \mathbf{k})$ microscopic image of electrolytically polymerized rubber facing anode by optical microscope; $(\mathbf{f}, \mathbf{l})$ microscopic image of electrolytically polymerized rubber facing cathode by optical microscope.

As for the MCF rubbers shown in Figures 11 and 12, the induced voltage and electric current as in piezo-electricity and piezo-resistivity, respectively, which repeatedly apply pressure, are shown in Figures 14 and 15. The change in induced voltage due to pressure is small, whereas the electric current 
has an unexpected surge response to pressure. At any rate, non-diene type MCF rubber, combined with water-insoluble or water-based MF by the emulsion polymerization of PVA and by mixing soluble rubber such as NR-latex or CR-latex, can have the feasibility of sensing.

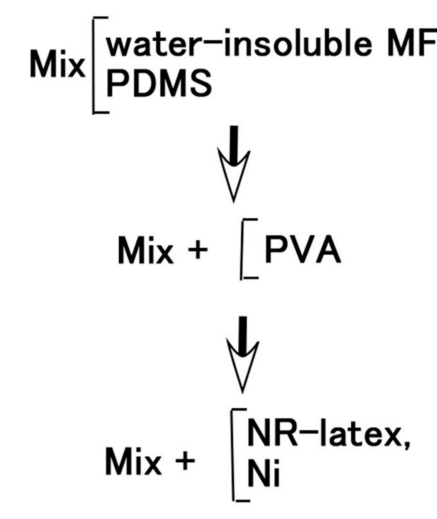

(a)

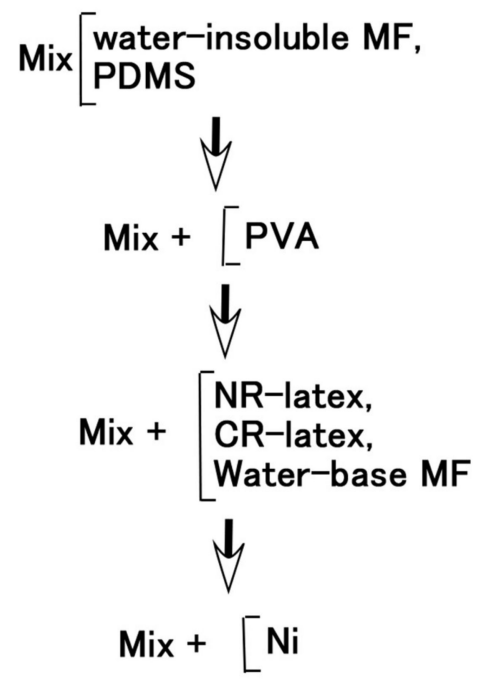

(b)

Figure 13. Mixing process for: (a) Figure 11; (b) Figure 12.

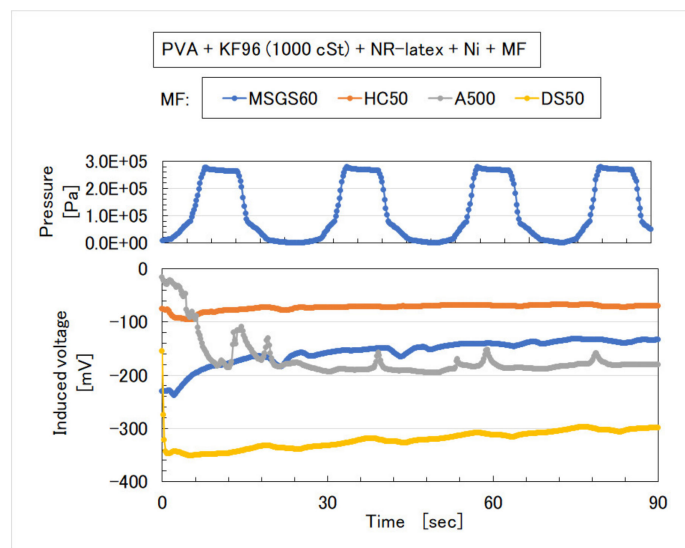

(a)

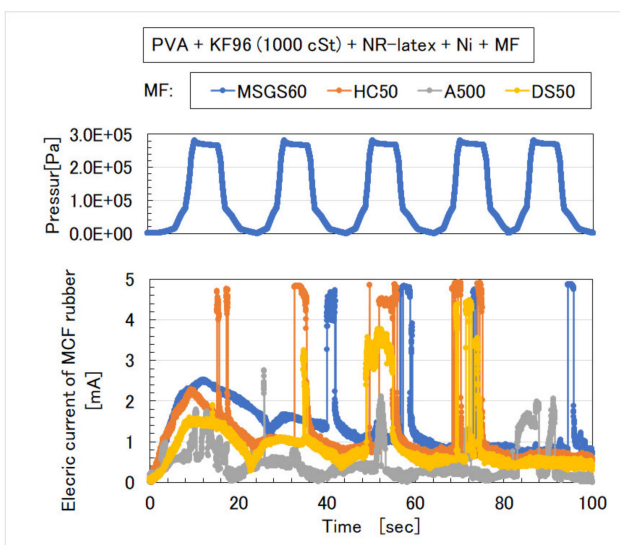

(b)

Figure 14. Induced voltage and electric current as piezo-resistivity of MCF rubber with KF96 and water-insoluble MF to repeat application of pressure in Figure 6: (a) piezo-electricity; (b) piezo-resistivity. 


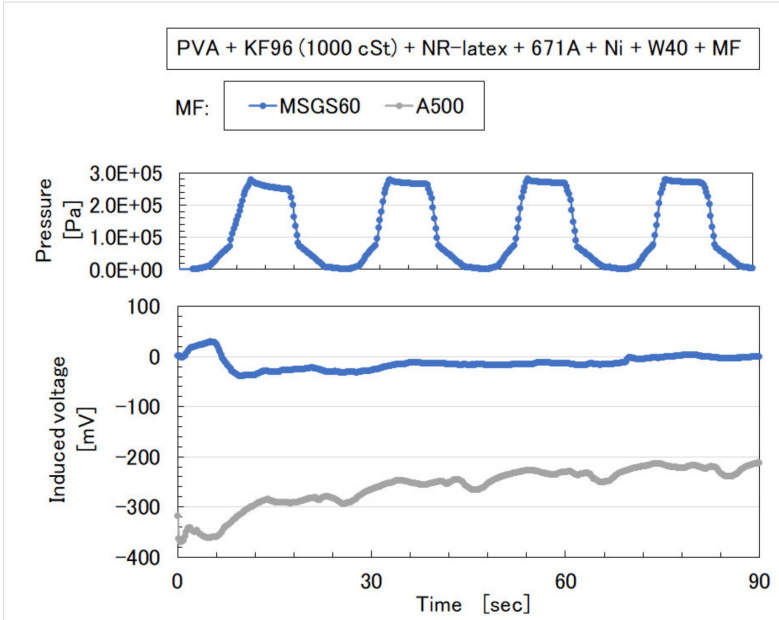

(a)

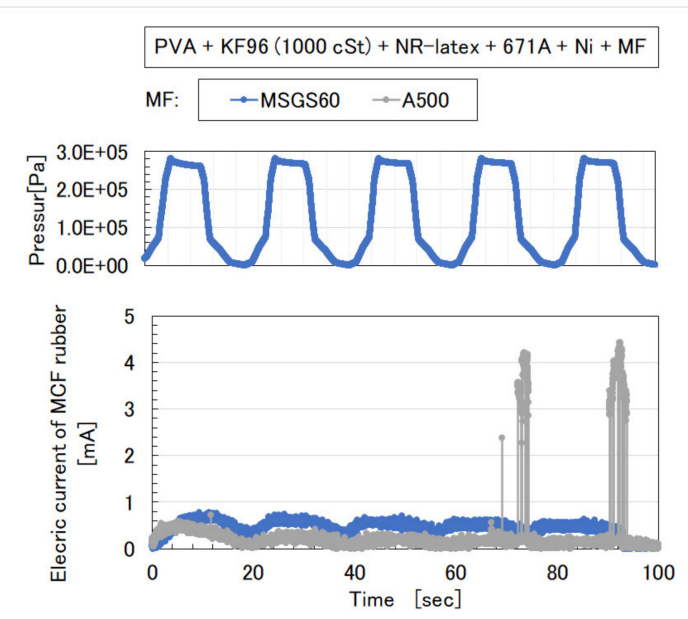

(b)

Figure 15. Induced voltage and electric current as piezo-resistivity of MCF rubber with KF96, water-insoluble MF, and water-based MF to repeat application of pressure in Figure 7: (a) piezo-electricity; (b) piezo-resistivity.

\subsection{Surfactant}

From the above results, the role played by the emulsion polymerization of PVA is significant in the electrolytic polymerization of combined diene and non-diene rubbers with PVA as a surfactant. In addition, the surfactant of MF such as oleic acid has also role of the emulsion polymerization. Therefore, the possibility of using other surfactants in their electrolytic polymerization can be inferred. In general, the surfactants are categorized into four types as shown in Figure A2 (Appendix B): anionic, cationic, nonionic, and amphoteric. In this figure, the surfactants that can be used in electrolytic polymerization were designated a circle marks, whereas those that cannot were designated cross marks. The triangle mark denotes that the ability of electrolytic polymerization is different depending on the experimental condition. These results are shown in Table 1. A $312 \mathrm{mT}$ magnetic field and an electric field at $20 \mathrm{~V}$ and $2.7 \mathrm{~A}$ were applied for $5 \mathrm{~min}$ with a $1 \mathrm{~mm}$ gap between electrodes. In this study, to investigate the possibility of mixing and electrolytic polymerization with NR-latex, the authors address Q rubber. Q can be divided into four types: KE1300T (Shin-Etsu Chemical Co. Ltd.), KE1400 (Shin-Etsu Chemical Co. Ltd.), KF96 (1000 cSt), and KF96 (1 cSt). KE1400 and KE1300T are silicone oils with some silane compounds and they are different from KF96, which is a pure silicone oil without any silane. Therefore, they are solidified to become solid silicone rubber using a curing agent.

According to the molecular weight of PDMS, the viscosity of KF96 changes: KF96 of 1 cSt is smaller than KF96 of $1000 \mathrm{cSt}$. The authors used $3 \mathrm{~g}$ Q, $0.75 \mathrm{~g}$ surfactant, $0.75 \mathrm{~g}$ MF (W40), $3 \mathrm{~g}$ NR-latex, and $3 \mathrm{~g}$ Ni. The mixing type used was $\mathrm{Q}$, surfactant, NR-latex, and Ni; and $\mathrm{Q}$, surfactant, MF, NR-latex, and Ni. KE1400 and KE1300T, which are predominantly silicone oils with some silane, cannot be mixed with NR-latex. If NR-latex is not mixed, the rubber liquid cannot be electrolytically polymerized. Additionally, anionic surfactant contributes to the mixing of water-solvent and water-insolvent rubbers, including the electrolytic polymerization of the mixed rubber. The contributions made by the anionic surfactant is more than that made by the cationic one. These outcomes occur owing to the emulsion polymerization of the surfactant. Consequently, electrolytic polymerization is created by a surfactant; however, the kind of surfactant to be used is a significant factor to consider. 
Table 1. Results of the possibility of mixing and electrolytic polymerization with surfactant and Q rubber liquid.

\begin{tabular}{|c|c|c|c|c|c|}
\hline Surfactant & Two Types of Mixing & Mixing + KE1300T & Mixing + KE1400 & Mixing + KF96 (1000 cSt) & Mixing + KF96 (1 cSt) \\
\hline \multirow{2}{*}{ Sodium oleate solution ${ }^{3}$} & + NR-latex & $x^{1}$ & $x$ & $\bigcirc^{2}$ & o \\
\hline & + NR-latex, MF & $x$ & $x$ & ○ & 0 \\
\hline \multirow{2}{*}{ Sodium lauric solution ${ }^{3}$} & + NR-latex & $x$ & $x$ & 0 & o \\
\hline & + NR-latex, MF & $x$ & $x$ & 0 & 0 \\
\hline \multirow{2}{*}{ Sodium naphthalene sulfonate solution ${ }^{3}$} & + NR-latex & $x$ & $x$ & $x$ & 0 \\
\hline & + NR-latex, MF & $x$ & $x$ & $\times$ & $\times$ \\
\hline \multirow{2}{*}{ Sodium hexadesyl sulfate solution ${ }^{3}$} & + NR-latex & $x$ & $x$ & O & O \\
\hline & + NR-latex, MF & $x$ & $x$ & 0 & $\times$ \\
\hline \multirow{2}{*}{ Sodium dodesyl sulfate solution ${ }^{3}$} & + NR-latex & $x$ & $x$ & O & O \\
\hline & + NR-latex, MF & $x$ & $x$ & 0 & 0 \\
\hline \multirow{2}{*}{ Tetramethylammonium hydroxy solution ${ }^{4}$} & + NR-latex & $x$ & $x$ & $\times$ & $\times$ \\
\hline & + NR-latex, MF & 0 & $x$ & 0 & $\times$ \\
\hline \multirow{2}{*}{ Benzethonium chloride ${ }^{4}$} & + NR-latex & $x$ & $x$ & O & $x$ \\
\hline & + NR-latex, MF & $x$ & $x$ & $x$ & $x$ \\
\hline \multirow{2}{*}{ Methylammonium chloride solution ${ }^{4}$} & + NR-latex & $x$ & $x$ & $x$ & $x$ \\
\hline & + NR-latex, MF & $\times$ & $x$ & $\bigcirc$ & $x$ \\
\hline \multirow{2}{*}{ Glycerol monostearic acid solution ${ }^{5}$} & + NR-latex & 0 & $\times$ & 0 & 0 \\
\hline & + NR-latex, MF & $\times$ & $x$ & 0 & \\
\hline \multirow{2}{*}{ Lauryl dimethylamylacetic acid solution ${ }^{6}$} & + NR-latex & $x$ & $x$ & O & O \\
\hline & + NR-latex, MF & $x$ & $\times$ & 0 & 0 \\
\hline \multirow{2}{*}{$\mathrm{N}, \mathrm{N}$-dimethyldesylamine $\mathrm{N}$-oxide solution ${ }^{6}$} & + NR-latex & $\times$ & $\times$ & 0 & 0 \\
\hline & + NR-latex, MF & $x$ & $x$ & 0 & 0 \\
\hline
\end{tabular}

${ }^{1} \mathrm{Q}$ rubber liquid cannot be mixed beforehand; ${ }^{2} \mathrm{Q}$ rubber liquid can be mixed and solidified by electrolytic polymerization.; ${ }^{3}$ anionic surfactant; ${ }^{4}$ cationic surfactant; ${ }^{5}$ nonionic surfactant; 6 amphoteric surfactant. 


\section{Consummate Fabrication of MCF Rubber Sensor}

By foregoing the electrolytic polymerization of MCF rubber, whether it is diene or non-diene rubber, rubber can be solidified differently from conventional vulcanization methods using a surfactant. Next, the authors manage the problem of the consummate fabrication of the sensor by utilizing MCF rubber. This fabrication has two prerequisites of adhesion to electrodes and doping conditions.

Because sensing is performed by the measurement of electrical signals, electrodes need to be installed inside a sensor, enough to strictly adhere to the sensor. Regarding MCF rubber sensor, plate or wire type electrodes are required not to be removed from the rubber. Consequently, a novel adhesion technique of using a hydrate such as $\mathrm{Na}_{2} \mathrm{WO}_{4} \cdot 2 \mathrm{H}_{2} \mathrm{O}$ is proposed [14]. The metal complex hydrate used is ionized in the compounded liquid with the MCF rubber, making the ion $\mathrm{WO}_{4}{ }^{2-}$ to become radical and vulcanized with isoprene molecules of water-soluble rubber by electrolytic polymerization. Additionally, on one hand, the MCF rubber adheres to the metal of the electrode at the anode side. On the other hand, to make the sensor exhibit varied sensing, force, temperature, and electromagnetic wave involving light doping or filling is quite often adopted. Mostly, the former used a chemical reagent as the dopant, whereas the latter used particle or powder as the filler. Regarding the MCF rubber sensor, various kinds of dopants were proposed and classified into three types: conductive, piezo, and battery types, as shown in Table A1 (Appendix C) [14]. The $\mathrm{TiO}_{2}$ or $\mathrm{Ni}$ involved in the $\mathrm{MCF}$ rubber corresponded to the filler.

However, the optimum adjustment of the conditions of the voltage and electric current of an electric field, its application period, magnetic field strength, electrodes gap, kind of electrodes, each component of the MCF rubber, and dopant on the electrolytic polymerization is needed so that the typical MCF rubber's characteristics might be exhibited. This is also because of the aridity caused by extreme electrolytic polymerization and the impossibility of electrolytic polymerization, whose phenomena are initial solidification at the mixing, owing to non-congeniality between the MCF rubber and dopant. Therefore, to resolve this doping condition, the authors propose a new technique that involves doping directly into the solid rubber.

\subsection{Rubber Stocking}

Because solid rubber is generally impermeable, conventional solid rubber cannot be directly doped by any reagent. However, any liquid can permeate the electrolytically polymerized MCF rubber, as shown in Figure 16. KF96 contains 1000 cSt, whereas MF is W40. A 312 mT magnetic field and an electric field at $30 \mathrm{~V}$ and $2.7 \mathrm{~A}$ are applied for $5 \mathrm{~min}$ with a $1 \mathrm{~mm}$ gap between electrodes. These figures show water-soluble types and mixtures of water-soluble and water-insoluble rubber types with MCF rubbers. In Figure 16b,d, water can be seen as the shimmering reflection of light on the rubber surface after permeation.

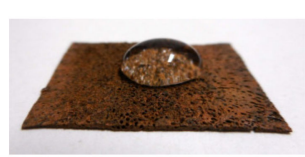

(a)

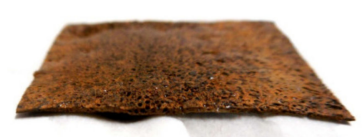

(b)

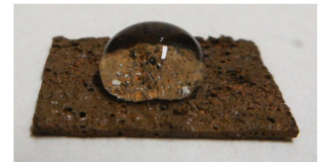

(c)

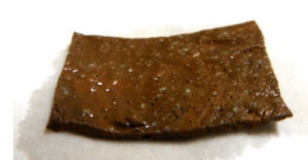

(d)

Figure 16. Images of MCF rubber before and after water permeation: (a) before permeation ( $0.75 \mathrm{~g} \mathrm{MF}$, $0.5 \mathrm{~g} \mathrm{TiO}_{2}, 3 \mathrm{~g} \mathrm{~S}-500,3 \mathrm{~g}$ 671A, and $3 \mathrm{~g} \mathrm{Ni}$ ); (b) after permeation (0.75 g MF, $0.5 \mathrm{~g} \mathrm{TiO}$, $3 \mathrm{~g}$ S-500, $3 \mathrm{~g}$ 671A, and $3 \mathrm{~g} \mathrm{Ni}$ ); (c) before permeation ( $3 \mathrm{~g} \mathrm{KF96,} 3 \mathrm{~g}$ PVA, $0.75 \mathrm{~g} \mathrm{MF}, 0.5 \mathrm{~g} \mathrm{TiO}$, $3 \mathrm{~g}$ S-500, $3 \mathrm{~g}$ 671A, and $3 \mathrm{~g}$ Ni); (d) after permeation (3 g KF96, 3 g PVA, $0.75 \mathrm{~g} \mathrm{MF}, 0.5 \mathrm{~g} \mathrm{TiO}$, $3 \mathrm{~g}$ S-500, $3 \mathrm{~g}$ 671A, and $3 \mathrm{~g} \mathrm{Ni}$ ).

However, as lapsing occurs after a long time of electrolytic polymerization, the MCF rubber is arid such that it takes a long time for water to permeate into the MCF rubber. Subsequently, when the MCF rubber is immersed in some liquid and the ambiance is evacuated, the liquid can be permeated into the MCF rubber. Furthermore, if the MCF rubber gets much more porous, more liquid 
can be permeated into the MCF rubber. Whether the MCF rubber is a water-soluble type or a combination of water-soluble and water-insoluble rubber type, by combining either metal complex hydrate $\mathrm{Na}_{2} \mathrm{WO}_{4} \cdot 2 \mathrm{H}_{2} \mathrm{O}$ with water, or mixing their blend, MCF rubber got much more porous such as in stocking. For example, many stocking- or sponge-like porosis can be seen, as shown in image of Figure 17 ao which is magnified on Figure 17k by scanning electron microscope (SEM). Compared to the MCF rubber without porosity, as shown in Figure 17a-e corresponding to Figure 16a,b, the MCF rubber stocking is shown in Figure 17f-an. A $312 \mathrm{mT}$ magnetic field and an electric field at $30 \mathrm{~V}$ and $2.7 \mathrm{~A}$ are applied for $5 \mathrm{~min}$ with a $1 \mathrm{~mm}$ gap between the electrodes. By adding metal complex hydrate $\mathrm{Na}_{2} \mathrm{WO}_{4} \cdot 2 \mathrm{H}_{2} \mathrm{O}$, porosity gets proliferated but by adding water, they multiply, as seen from the image of rubber transmitted by the light in Figure $17 \mathrm{a}, \mathrm{f}, \mathrm{k}, \mathrm{p}, \mathrm{u}, \mathrm{z}, \mathrm{ae}, \mathrm{aj}$. The porosity is so large that the authors can confirm its existence in the rubber. Multiple repeated electrolytic polymerizations mean that the $\mathrm{MCF}$ rubber liquid has the same ingredient smothered on the once electrolytically polymerized MCF rubber, and then electrolytically polymerized again, such that the electrolytically polymerized MCF rubber creates multi-layers. Therefore, by comparing Figure $17 \mathrm{k}, \mathrm{p}, \mathrm{u}$ or Figure $17 \mathrm{z}, \mathrm{ae}, \mathrm{aj}$, it can be deduced that the more electrolytic polymerization conducted, the less porosity created. The MCF rubber with many porous spaces can contain liquids by evacuation. Examples of microscopic images of the MCF rubber permeated by a reagent is presented in Figure 18. The MCF rubber was electrolytically polymerized thrice, where $\mathrm{KI}+\mathrm{I}_{2}$ represents the $\mathrm{KI}$ solution, which is an aqueous potassium iodide solution made up of $60 \mathrm{~g}$ of water and $40 \mathrm{~g}$ of potassium iodide. KF96 contains $1000 \mathrm{cSt}$, whereas the MF used is W40. A $312 \mathrm{mT}$ magnetic field and an electric field at $30 \mathrm{~V}$ and $2.7 \mathrm{~A}$, are applied for $5 \mathrm{~min}$ with a $1 \mathrm{~mm}$ gap between the electrodes.

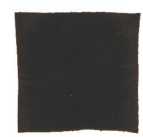

(a)

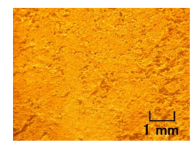

(e)

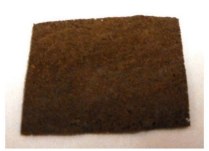

(i)

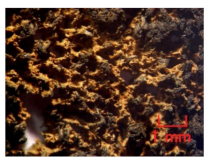

$(\mathbf{m})$

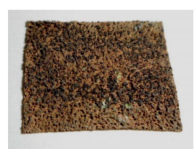

$(\mathbf{q})$

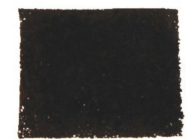

(u)

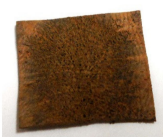

(b)

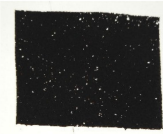

(f)

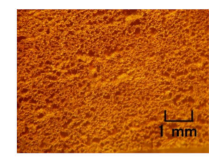

(j)

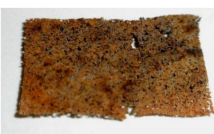

(n)

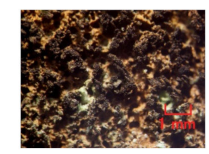

(r)

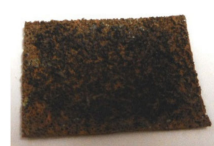

(v)

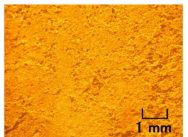

(c)

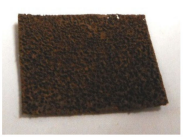

(g)

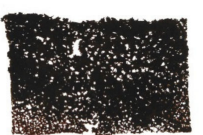

(k)

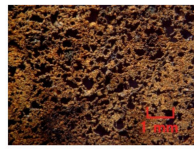

(o)

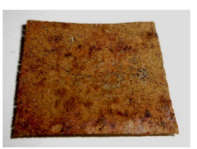

(s)

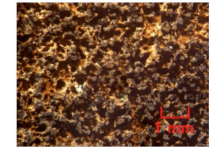

(w)

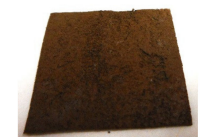

(d)

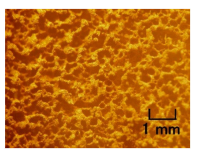

(h)

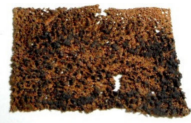

(1)

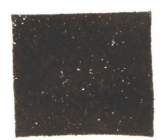

(p)

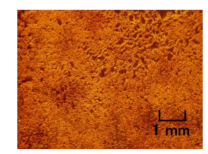

(t)

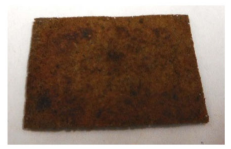

(x)

Figure 17. Cont. 


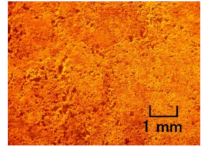

(y)

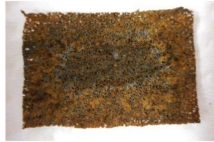

(ac)

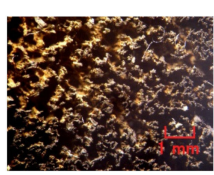

(ag)

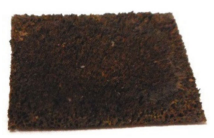

(ak)

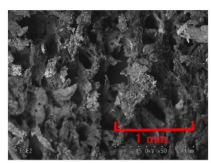

(ao)

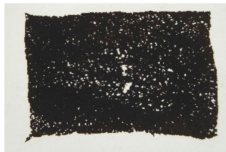

(z)

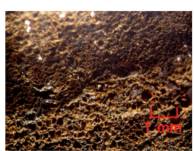

(ad)

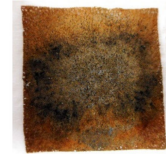

(ah)

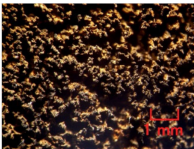

(al)

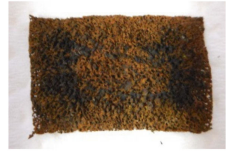

(aa)

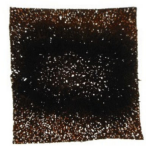

(ae)

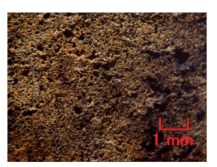

(ai)

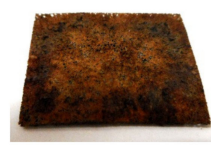

(am)

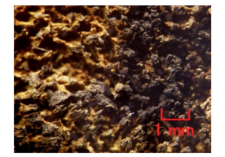

(ab)

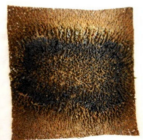

(af)

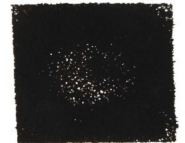

(aj)

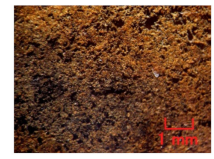

(an)

Figure 17. Images of electrolytically polymerized rubber: (a-e) $0.75 \mathrm{~g} \mathrm{MF}, 0.5 \mathrm{~g} \mathrm{TiO}_{2}, 3 \mathrm{~g}$ S-500, $3 \mathrm{~g}$

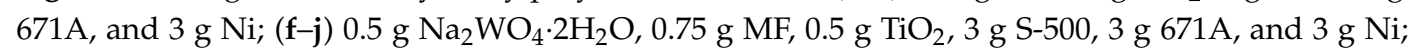
(k-y) $0.5 \mathrm{~g} \mathrm{Na}_{2} \mathrm{WO}_{4} \cdot 2 \mathrm{H}_{2} \mathrm{O}, 3 \mathrm{~g}$ water, $0.75 \mathrm{~g} \mathrm{MF}, 0.5 \mathrm{~g} \mathrm{TiO}_{2}, 3 \mathrm{~g} \mathrm{~S}-500,3 \mathrm{~g} 671 \mathrm{~A}$, and $3 \mathrm{~g} \mathrm{Ni}$; (z-an) $0.5 \mathrm{~g}$ $\mathrm{Na}_{2} \mathrm{WO}_{4} \cdot 2 \mathrm{H}_{2} \mathrm{O}, 3 \mathrm{~g}$ water, $3 \mathrm{~g}$ KF96 (1000 cSt), $3 \mathrm{~g}$ PVA, $0.75 \mathrm{~g} \mathrm{MF}, 0.5 \mathrm{~g} \mathrm{TiO}$, 3 g S-500, $3 \mathrm{~g}$ 671A, and $3 \mathrm{~g}$ $\mathrm{Ni}$; (a-o), (z-ad) electrolytic polymerization conducted one time; (p-t,ae-ai) electrolytic polymerization conducted two times; (u-y,aj-an) electrolytic polymerization conducted three times; (a,f, $\mathbf{k}, \mathbf{p}, \mathbf{u}, \mathbf{z}, \mathbf{a e}, \mathbf{a j})$ panoramic image of rubber facing cathode transmitted by light; (b,g,l, $\mathbf{q}, \mathbf{v}, \mathbf{a a}, \mathbf{a f}, \mathbf{a k})$ panoramic image of rubber facing cathode; (c,h, $\mathbf{m}, \mathbf{r}, \mathbf{w}, \mathbf{a b}, \mathbf{a g}, \mathbf{a l})$ microscopic image of rubber facing cathode by optical microscope; (d, $\mathbf{i}, \mathbf{n}, \mathbf{s}, \mathbf{x}, \mathbf{a c}, \mathbf{a h}, \mathbf{a m})$ panoramic image of rubber facing anode; (e,j, $\mathbf{o}, \mathbf{t}, \mathbf{y}, \mathbf{a d}, \mathbf{a i}, \mathbf{a n})$ microscopic image of rubber facing anode by optical microscope; (ao) microscopic image of (k) by SEM with $50 \times$ magnification.

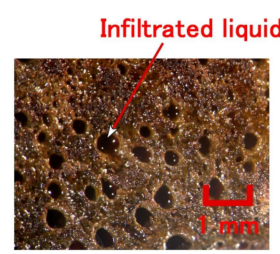

(a)

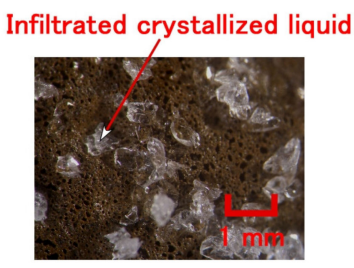

(b)

Figure 18. Images of porous MCF rubber after percolation by evacuation $\left(0.5 \mathrm{~g} \mathrm{Na}_{2} \mathrm{WO}_{4} \cdot 2 \mathrm{H}_{2} \mathrm{O}, 3 \mathrm{~g}\right.$ KF96, 3 g PVA, 0.75 g MF, 0.5 g TiO$_{2}$, 3 g S-500, 3 g 671A, and $3 \mathrm{~g} \mathrm{Ni}$ ): (a) $\mathrm{KI}+\mathrm{I}_{2}$; (b) adipic acid.

In the production of MCF rubber stocking, many peculiarities can be confirmed: the temperature and electrical properties during the electrolytic polymerization, and its adhesion to the electrodes as follows. Firstly, Figure 19 shows the time-lapse from the start of the application of an electric field, which indicates "on," where MCF rubber 1 is represented in the figure corresponding to Figure 17a-e (0.75 g MF, $0.5 \mathrm{~g} \mathrm{TiO}_{2}, 3 \mathrm{~g}$ S-500, $3 \mathrm{~g}$ 671A, and $3 \mathrm{~g} \mathrm{Ni}$ ), MCF rubber 2 corresponding to Figure 17f-j 
( $0.5 \mathrm{~g} \mathrm{Na}_{2} \mathrm{WO}_{4} \cdot 2 \mathrm{H}_{2} \mathrm{O}, \mathrm{MF}, 0.5 \mathrm{~g} \mathrm{TiO}{ }_{2}, 3 \mathrm{~g}$ S-500, $3 \mathrm{~g} 671 \mathrm{~A}$, and $3 \mathrm{~g} \mathrm{Ni}$ ), and MCF rubber 3 corresponding to Figure $17 \mathrm{k}-\mathrm{y}\left(0.5 \mathrm{~g} \mathrm{Na}_{2} \mathrm{WO}_{4} \cdot 2 \mathrm{H}_{2} \mathrm{O}, 3 \mathrm{~g}\right.$ water, $0.75 \mathrm{~g} \mathrm{MF}, 0.5 \mathrm{~g} \mathrm{TiO} 2,3 \mathrm{~g} \mathrm{~S}-500,3 \mathrm{~g} 671 \mathrm{~A}$, and $\left.3 \mathrm{~g} \mathrm{Ni}\right)$. MF is W40. A $312 \mathrm{mT}$ magnetic field and an electric field at $30 \mathrm{~V}$ and $2.7 \mathrm{~A}$ are applied for $5 \mathrm{~min}$ with a $1 \mathrm{~mm}$ gap between electrodes. By adding metal complex hydrate $\mathrm{Na}_{2} \mathrm{WO}_{4} \cdot 2 \mathrm{H}_{2} \mathrm{O}$ and more water, temperature becomes higher and it takes a longer time for electric current to culminate and for voltage to reach $30 \mathrm{~V}$. The enhancement of temperature and delay occurs because the process of electrolytic polymerization takes time.

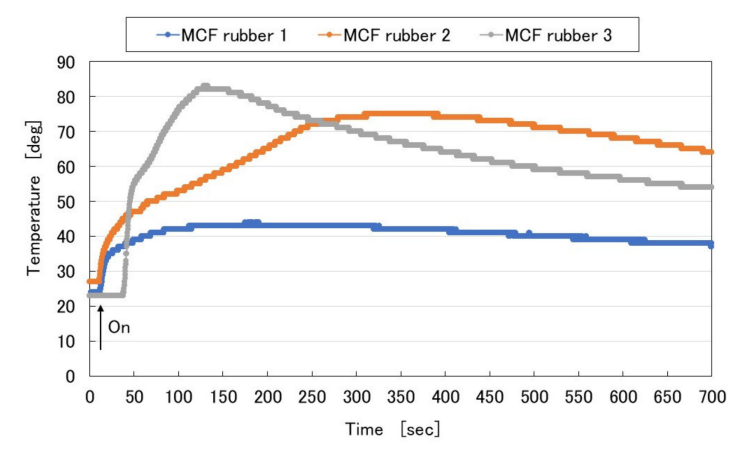

(a)

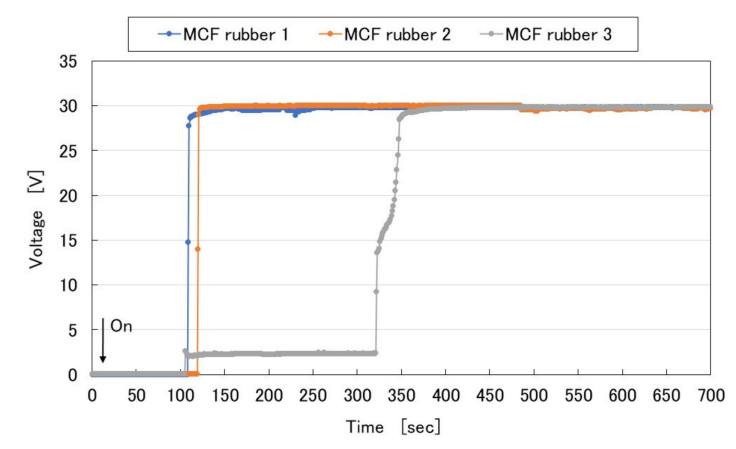

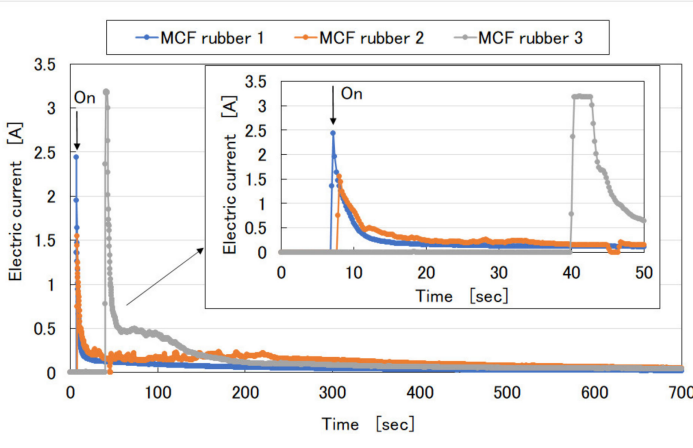

(b)

(c)

Figure 19. Change in temperature, electric current, and voltage of MCF rubber liquid during electrolytic polymerization: (a) temperature; (b) current; (c) voltage.

Secondly, the electrolytically polymerized MCF rubber strictly adheres to the anode such that it is difficult to detach the MCF rubber from the electrode. This peculiarity differs according to the kind of electrode used. The strict adhesion occurs on stainless steel, aluminum, titanium, nickel, zinc, lead, brass, iron, and copper. This adhesion occurs owing to the balance between the work function and redox potentials of the metal of the electrode, and the metal complex hydrate $\mathrm{Na}_{2} \mathrm{WO}_{4} \cdot 2 \mathrm{H}_{2} \mathrm{O}$, which has been clarified in the previous study [14]. In contrast, the MCF rubber cannot adhere to titanium and chromium. Therefore, judging from the ease of detaching the MCF rubber from the electrode, these materials should be used. However, the possibility of solidifying the MCF rubber liquid by electrolytic polymerization varies depending on the constituents of the MCF rubber. Table 2 shows the results of solidification by electrolytic polymerization and the color of anode after electrolytic polymerization in the case titanium. In the case of chromium, the MCF rubber can be solidified by electrolytic polymerization regardless of any constituent of the MCF rubber. KF96 has 1000 cSt and MF is W40. A $312 \mathrm{mT}$ magnetic field and an electric field at $20 \mathrm{~V}$ (or $30 \mathrm{~V}$ ) and $2.7 \mathrm{~A}$ are applied for $5 \mathrm{~min}$ with a $1 \mathrm{~mm}$ gap between the electrodes. The liquid dye presented in the table is always used in a solar cell. 
Table 2. Results of solidification by electrolytic polymerization and color of anode after the electrolytic polymerization in the case of titanium anode.

\begin{tabular}{|c|c|c|c|c|c|c|c|c|c|c|c|}
\hline $\begin{array}{l}\text { NR-Latex } \\
\quad[g]\end{array}$ & $\begin{array}{c}671 \mathrm{~A} \\
{[\mathrm{~g}]}\end{array}$ & $\begin{array}{c}\text { KF96 } \\
{[\mathrm{g}]}\end{array}$ & $\begin{array}{c}\text { PVA } \\
{[g]}\end{array}$ & $\begin{array}{l}\text { MF } \\
{[g]}\end{array}$ & Ni [g] & $\begin{array}{c}\mathrm{TiO}_{2} \\
{[\mathrm{~g}]}\end{array}$ & $\begin{array}{l}\text { Voltage } \\
\text { [V] }\end{array}$ & $\begin{array}{c}\text { Dopant } \\
\text { [g] }\end{array}$ & $\underset{[\mathrm{g}]}{\mathrm{Na}_{2} \mathrm{WO}_{4} \cdot 2 \mathrm{H}_{2} \mathrm{O}}$ & Rubber $^{1}$ & Color $^{2}$ \\
\hline 3 & & & & 0.75 & 3 & & 6 & & & $S^{4}$ & $\mathrm{NC}^{7}$ \\
\hline 3 & & & & 0.75 & 3 & 0.5 & 6 & & & $S^{4}$ & $\mathrm{NC}^{7}$ \\
\hline 3 & 3 & 3 & 3 & 0.75 & 3 & & 6 & & & $\mathrm{~N}^{5}$ & $\mathrm{NC}^{7}$ \\
\hline 3 & 3 & 3 & 3 & 0.75 & 3 & & 20.30 & & & PS $^{6}$ & $\mathrm{P}^{8}$ \\
\hline 3 & 3 & 3 & 3 & 0.75 & 3 & & 30 & Dye $^{3}$ & & $\mathrm{~S}^{4}$ & $\mathrm{P}^{8}$ \\
\hline 3 & 3 & 3 & 3 & 0.75 & 3 & 0.5 & 6 & & & $\mathrm{~N}^{5}$ & $\mathrm{NC}^{7}$ \\
\hline 3 & 3 & 3 & 3 & 0.75 & 3 & 0.5 & 20 & & & $\mathrm{~N}^{5}$ & $\mathrm{P}^{8,9}$ \\
\hline 3 & 3 & 3 & 3 & 0.75 & 3 & 0.5 & 30 & & & PS $^{6}$ & $\mathrm{P}^{8}$ \\
\hline 3 & 3 & 3 & 3 & 0.75 & 3 & 0.5 & 30 & Dye $^{3}$ & & $S^{4}$ & $\mathrm{P}^{8}$ \\
\hline 3 & 3 & 3 & 3 & 0.75 & 3 & & 30 & Dye $^{3}$ & & $S^{4}$ & $\mathrm{P}^{8}$ \\
\hline 3 & 3 & 3 & 3 & 0.75 & 3 & & 6 & & 0.5 & $\mathrm{~N}^{5}$ & $\mathrm{NC}^{7}$ \\
\hline 3 & 3 & 3 & 3 & 0.75 & 3 & & 30 & & 0.5 & $\mathrm{PS}^{6}$ & $\mathrm{P}^{8}$ \\
\hline 3 & 3 & 3 & 3 & 0.75 & 3 & 0.5 & 6 & & 0.5 & $\mathrm{~N}^{5}$ & $\mathrm{NC}^{7}$ \\
\hline 3 & 3 & 3 & 3 & 0.75 & 3 & 0.5 & 30 & & 0.5 & PS $^{6}$ & $\mathrm{P}^{8}$ \\
\hline
\end{tabular}

1 electrolytic polymerization; ${ }^{2}$ Color of anode after electrolytic polymerization; ${ }^{3}$ Liquid dye based on Ruthenium complexes PEC-TOM-P04 (Peccell Technologies Co. Ltd., Yokohama, Japan); ${ }^{4} \mathrm{~S}$ means solidified; ${ }^{5} \mathrm{~N}$ means not solidified; ${ }^{6} \mathrm{PS}$ means partially solidified; ${ }^{7} \mathrm{NC}$ means not changing color; ${ }^{8} \mathrm{P}$ means changing to blue purple; ${ }^{9}$ see Figure 20.

In the case of titanium, just anode electrode changes blue color purple, as shown in Table 2 and Figure 20. This phenomenon is related to the titanium oxide coating. Therefore, by utilizing MCF rubber, titanium can be coated. This can be proposed as another novel technique of utilizing MCF rubber.

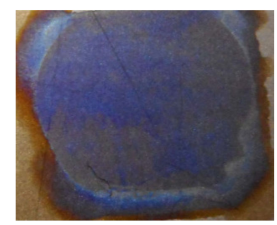

Figure 20. Images of titanium anode after electrolytic polymerization designating 9 in Table 2.

Rubber stocking is useful in diverse ways except as the infiltrating material in the present MCF rubber sensing, for example, it is effective for filter and odor sensing [26]. As for the latter, the voltage between the ends of the rubber stocking, which is changed by the ionized molecular inserted into the hollows, can be measured.

\subsection{Consummate Fabrication}

Using the foregoing percolation technique of permeating a reagent into the MCF rubber, as well as the adhesion technique of electrode wires on the MCF rubber of the previous study [14], a consummate fabrication of the MCF rubber sensor is proposed, as shown in Figure 21. For the adhesion technique produced "(a) adhesive MCF rubber 2" as shown in the figure preliminarily. By the percolation technique, porous MCF rubber 1 is electrolytically polymerized three times and permeated by a reagent: "(c) porous MCF rubber 1" as shown in the figure. However, the authors produce "(e) electrolytically polymerized MCF rubber 3" as shown in the figure, and this rubber does not have $\mathrm{Na}_{2} \mathrm{WO}_{4} \cdot 2 \mathrm{H}_{2} \mathrm{O}$ and water because the roles of adhesion and infiltration used are not needed. "(e) electrolytically polymerized MCF rubber 3" is for the outer enclosure, and "(c) porous MCF rubber 1" is squeezed between them using liquid "(a) adhesive MCF rubber 2" and electrolytic polymerization, where electric wires are inserted inside the "(a) adhesive MCF rubber 2". Next, to prevent the MCF rubber sensor 
from drying, it is coated with silicone oil rubber (KE1300T) with curing reagent. However, the surface of the produced MCF rubber sensor and the silicone oil rubber react to each other and cause them not to be solidified. This is another critical point of the production of the MCF rubber sensor. Therefore, "(d) liquid of MCF rubber 3" is initially coated on the produced MCF rubber sensor to be dried as "solidified MCF rubber 4" in the figure, and then the silicone oil rubber is coated to be dried.

One example of a specimen of the consummate MCF rubber sensor is shown in Figure 22a and its cross-section in Figure 22b. The MCF rubber inside the silicone oil rubber is $16 \mathrm{~mm} \times 21.5 \mathrm{~mm}$ in size and $4 \mathrm{~mm}$ thick, and the size of the outer shell of silicone oil rubber is $16.5 \mathrm{~mm} \times 24 \mathrm{~mm}$ and $4.5 \mathrm{~mm}$ thick.

As seen in previous sections, solid MCF rubber is permeable, which is a peculiar property. However, as regards to filling, to make it conductive, as shown in Table A1 (Appendix C), tin-plated thin and short copper wires (AWG12 type, Kyowa Harmonet Co. Ltd., Kyoto, Japan) with $\phi 0.12 \mathrm{~mm}$ diameter, and $2 \mathrm{~mm}$ length can be compounded in the MCF rubber by cutting them as fillers. Where the filler is viable to the inner compound of either "(a) adhesive MCF rubber 2" or "(c) porous rubber 1". Figure 23 shows the induced voltage of the MCF rubber sensor to repeated pressure by the production of Figure 21 in the case of porous MCF rubber 1 without thin wires and the adhesive MCF rubber 2 case with thin wires. Varied reagents are percolated into the porous MCF rubber 1 by evacuation while varied particles are compounded in the porous MCF rubber 1 by mixing. KF 96 has 1000 cSt and MF is W40. A $312 \mathrm{mT}$ magnetic field and an electric field at $2.7 \mathrm{~A}$ are applied with a $1 \mathrm{~mm}$ gap between the electrodes. The liquid of "(a) adhesive MCF rubber 2" contains $0.5 \mathrm{~g} \mathrm{Na}_{2} \mathrm{WO}_{4} \cdot 2 \mathrm{H}_{2} \mathrm{O}, 3 \mathrm{~g}$ water, $0.75 \mathrm{~g}$ MF, $3 \mathrm{~g}$ NR-latex (Ulacol), $3 \mathrm{~g}$ CR-latex (671A), and $3 \mathrm{~g}$ Ni. As for liquid of “(b) porous MCF rubber 1", it contains $0.5 \mathrm{~g} \mathrm{Na}_{2} \mathrm{WO}_{4} \cdot 2 \mathrm{H}_{2} \mathrm{O}, 3 \mathrm{~g}$ water, $0.75 \mathrm{~g} \mathrm{MF}, 3 \mathrm{~g}$ PDMS (KF96), $3 \mathrm{~g}$ PVA, $3 \mathrm{~g}$ NR-latex (Ulacol), $3 \mathrm{~g}$ CR-latex (671 A), $3 \mathrm{~g} \mathrm{TiO}_{2}$, and $3 \mathrm{~g} \mathrm{Ni}$. In the case of the liquid for "(d) MCF rubber 3," it contains $0.75 \mathrm{~g}$ MF, $3 \mathrm{~g}$ NR-latex (Ulacol), $3 \mathrm{~g}$ CR-latex (671A), $3 \mathrm{~g} \mathrm{TiO}{ }_{2}$, and $3 \mathrm{~g} \mathrm{Ni}$. $\mathrm{BaTiO}_{3}$ and $\mathrm{Al}_{2} \mathrm{O}_{3}(\mathrm{CR}$, $3 \mu \mathrm{m})$ are measured and used at $1 \mathrm{~g}$.

The MCF rubber sensor is sensitive enough to be practical by the percolation technique with reagents into the MCF rubber. The trends show that the induced voltage involving dielectric particles such as $\mathrm{Al}_{2} \mathrm{O}_{3}$ and $\mathrm{BaTiO}_{3}$ and non-conducting liquid such as glycerin become the largest among others. $\mathrm{BaTiO}_{3}$ is often used in the piezo-element. The cases with sodium hexadecyl sulfate solution $\left(\mathrm{C}_{16} \mathrm{H}_{33} \mathrm{NaO}_{4} \mathrm{~S}\right)$ which is anionic surfactant, with lithium hydroxide monohydrate $\left(\mathrm{LiOH} \cdot 2 \mathrm{H}_{2} \mathrm{O}\right)$ which is used as electrolyte of battery and lithium citrate tetrahydrate $\left(\mathrm{Li}_{3} \mathrm{C}_{6} \mathrm{H}_{5} \mathrm{O}_{7} \cdot 4 \mathrm{H}_{2} \mathrm{O}\right)$, are the second largest. Glycerin $\left(\mathrm{C}_{3} \mathrm{H}_{5}(\mathrm{OH})_{3}\right)$ is one emulsifier. Then the induced voltage with surfactant or emulsifier tends to be large. On the other hand, the induced voltage with particle-type dopant tends to be larger than the one with liquid-type. The other cases involving alkali aqueous solution such as $\mathrm{KOH}$ and $\mathrm{KI}+\mathrm{I}_{2}$, water, kerosene or kerosene-type liquid such as MSGS60, are the smallest. 

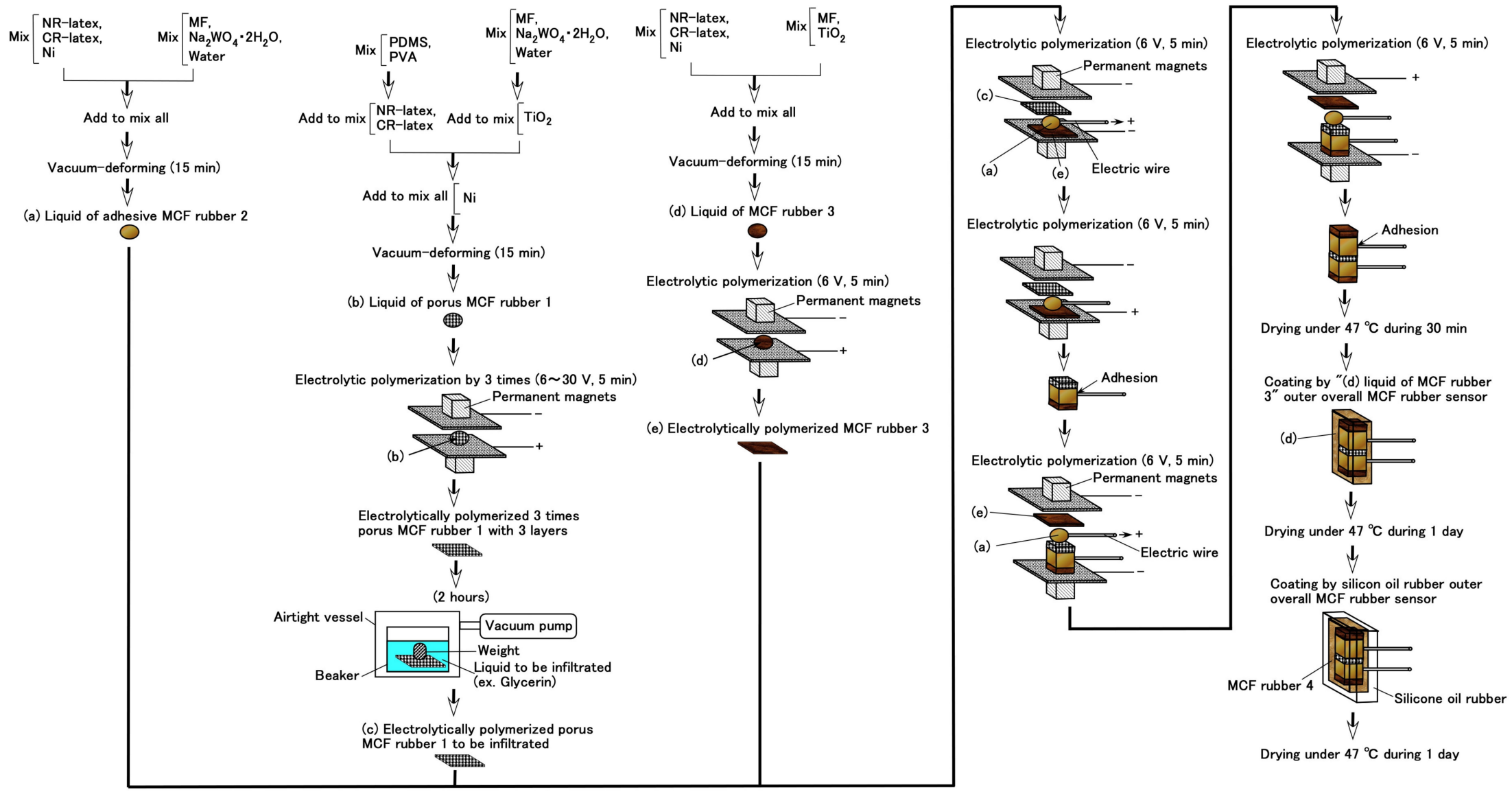

Figure 21. Production procedure of consummate fabrication of MCF rubber sensor. 


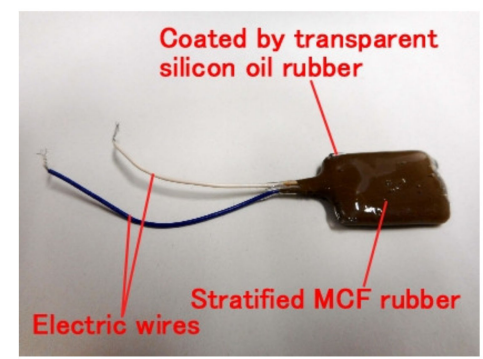

(a)

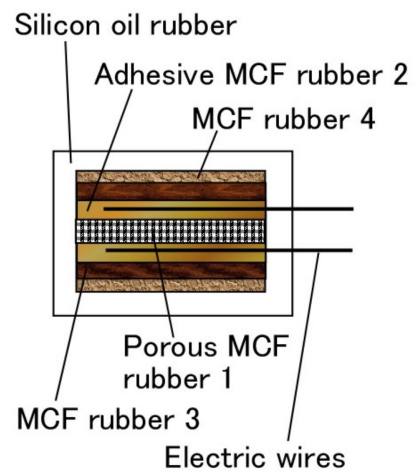

(b)

Figure 22. Specimen of the consummate MCF rubber sensor by the production process of Figure 21: (a) photograph; (b) schematic cross section.

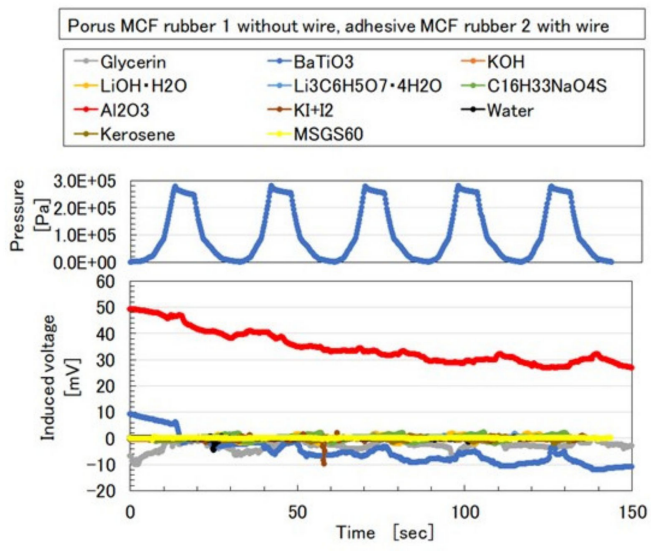

(a)
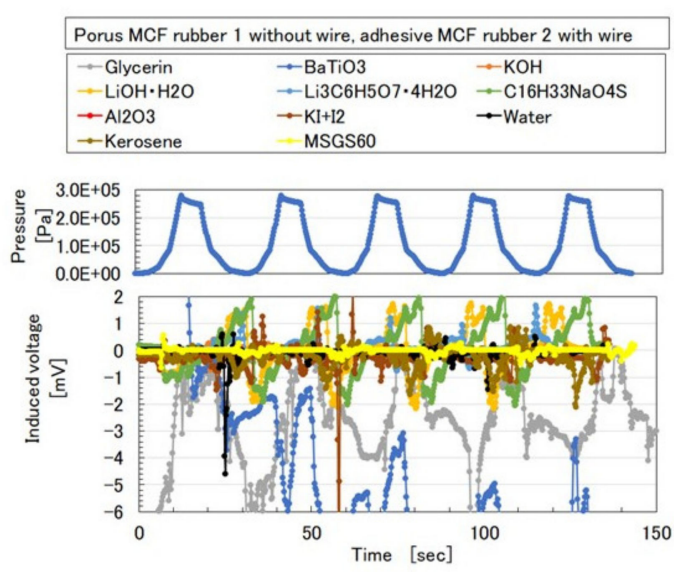

(b)

Figure 23. Induced voltage of MCF rubber sensor to repeated pressure by the production process of Figure 21: (a) zooming out of (b); (b) zooming in from (a).

\section{Conclusions}

The present first report offers the key to an understanding of practicability of electrolytic polymerization for the solidification of rubber with various combinations of diverse kinds of rubber, MF and emulsifier. And another critical point is about the fabrication of the MCF rubber sensor with their various combinations and the porous rubber permeated by any dopants. The production of the porous rubber (rubber stocking) and the permeation of any liquids into the rubber are also novel technique of the present study.

The authors presented the role of the emulsion polymerization of PVA, which is significant in the electrolytic polymerization of combined diene and non-diene rubbers. By dealing with $U$ as another non-diene rubber except for $Q$, the electrolytic polymerization technique is feasible, in which PVA is utilized and water-soluble diene rubber (NR-latex or CR-latex) is mixed with non-diene rubber. The Diene type MCF rubber mixed by water-insoluble liquid or water-insoluble MF using the emulsion polymerization of PVA had the feasibility of haptic sensing; therefore, non-diene type MCF rubber combined by mixing water-insoluble or water-based MF, with soluble rubber such as NR-latex or CR-latex, using the emulsion polymerization of PVA, can have the feasibility of sensing. Consequently, under the diverse combination of soluble and insoluble rubber, liquid or MF too, electrolytic polymerization can be conducted on soluble and insoluble rubbers, with insoluble 
rubber and MF, or soluble and insoluble MFs in the rubber. Additionally, the MCF rubber sensor produced by those compounded materials has a feasibility of sensing pressure as piezo-electricity and piezo-resistivity.

The utilization of PVA enables what was considered impossible until now, allowing the water-soluble rubber to combine with water-insoluble rubber or liquid to form a practical mixture. Because PVA is a surfactant, other surfactants are feasible in their electrolytic polymerization. In particular, the anionic surfactant tends to contribute to the mixing of water-soluble and water-insoluble rubbers, and the electrolytic polymerization of the mixed rubber.

Conventional solid rubber cannot be directly doped by any reagent because solid rubber is generally impermeable. However, any liquid can permeate the electrolytically polymerized MCF rubber. Whether the MCF rubber is a water-soluble type or a combination of water-soluble and water-insoluble rubber types, by combining either metal complex hydrate $\mathrm{Na}_{2} \mathrm{WO}_{4} \cdot 2 \mathrm{H}_{2} \mathrm{O}$ or water, or by combining their mixture, $\mathrm{MCF}$ rubber becomes much more porous such as stocking. The rubber stocking, which can also be percolated by any liquid, has certain peculiarities: the enhancement of temperature and the long period of electrolytic polymerization, and the strict adhesion of the electrolytically polymerized MCF rubber to the anode, which detaches the MCF rubber from the electrode. The percolation technique of permeating a reagent into the MCF rubber stocking is useful in the case of the infiltrating material to rubber.

Using the rubber stocking and the previously proposed adhesion technique of electric wires to the MCF rubber, the authors constructed a consummate fabrication process of the MCF rubber sensor. The MCF rubber sensor is sensitive so that the percolation technique of permeating a reagent into the MCF rubber is productive. The diverse specified examples of using the MCF rubber sensor are presented in another sequential second report [24].

Author Contributions: For this research article, K.S. conceived the idea, designed and performed the experiments, analyzed the data, and wrote the paper; H.K., H.T. and R.I. contributed reagents/materials/analysis tools and analyzed the data. All authors have read and agreed to the published version of the manuscript.

Funding: This work was supported in parts by JSPS KAKENHI Grant Number JP 18K04040 and by the Fukushima Innovation Coast Framework project "Namie Town Creation with Revitalizics using Risk Communication Engineering: for Realization of Innovation Coast Framework" in Japan.

Conflicts of Interest: The funding sponsors had no role in the design of the study. The authors declare no conflict of interest.

\section{Appendix A}

In general, rubber is categorized as shown in Figure A1.

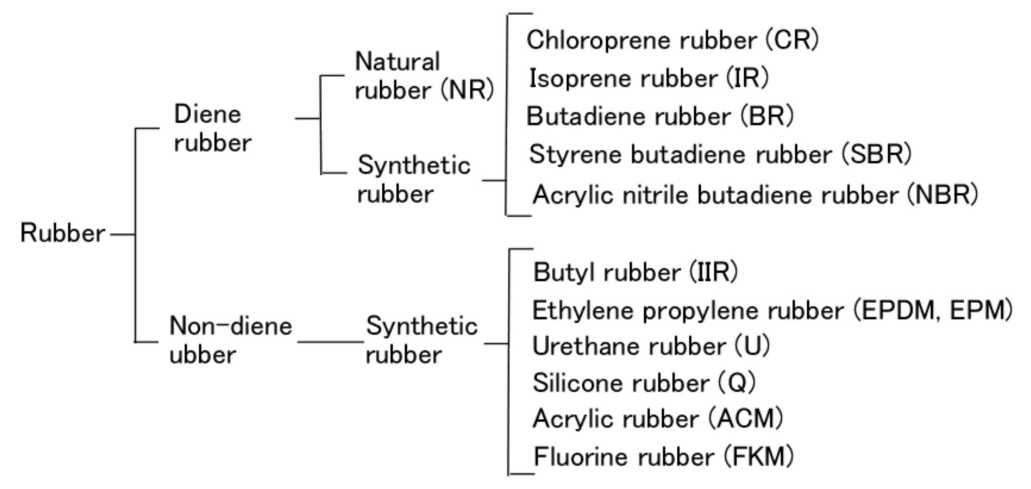

Figure A1. Classification of rubber.

\section{Appendix B}

In general, surfactant is categorized as shown in Figure A2. The circle marks in the figure denote that the surfactant can play a role in electrolytic polymerization, whereas the cross mark denotes 
that it cannot be used in electrolytic polymerization. The triangle mark denotes that the electrolytic polymerization ability of the surfactant differs depending on the experimental condition.

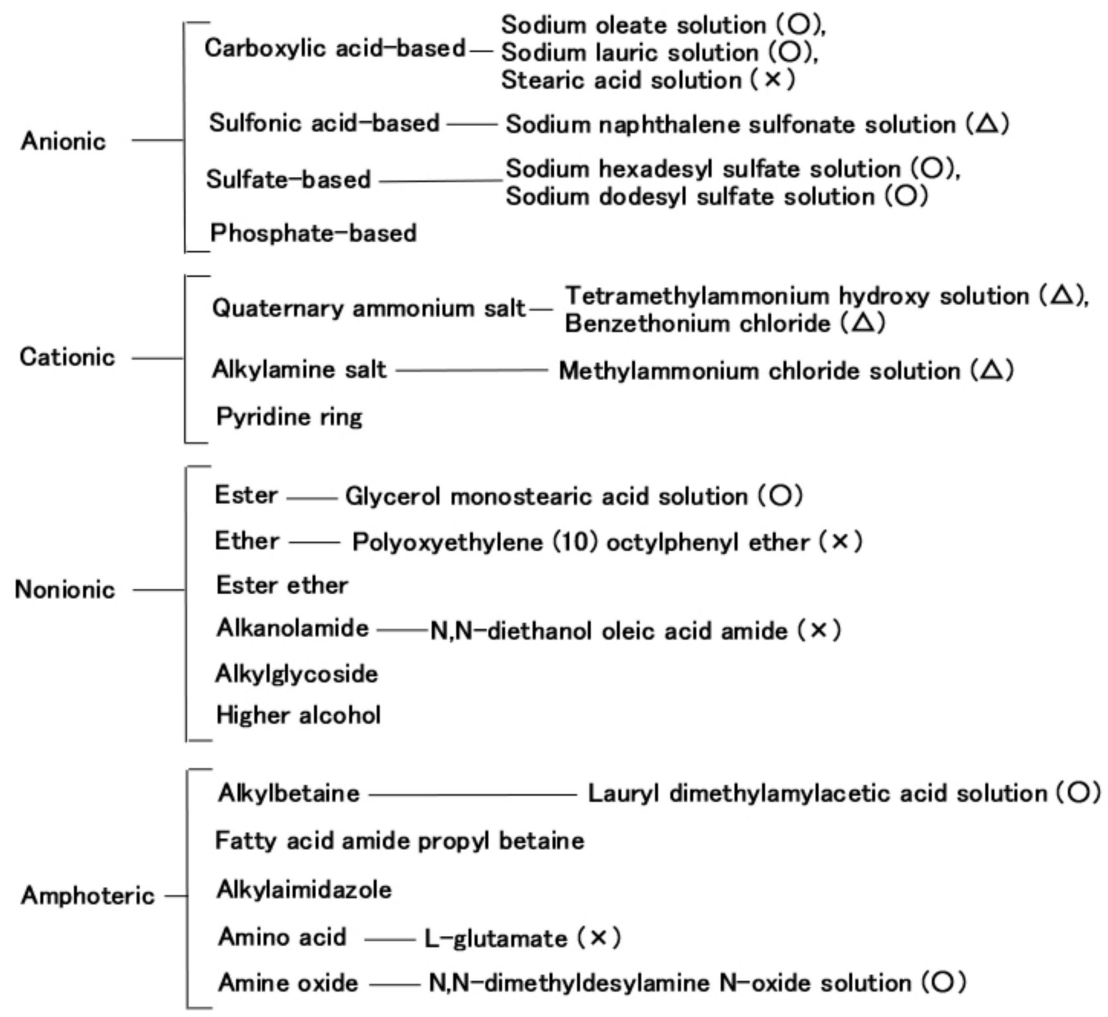

Figure A2. Classification of surfactant.

\section{Appendix C}

Depending on the type of dopant, MCF rubber obtained by electrolytic polymerization is mainly divided into three types with different electrical properties, as shown in Table A1 [14]. The MCF rubber has induced voltage and electric current. Typically, the value of electric resistance is directly proportional to the induced voltage, such that it rises when induced voltage increases and vice versa. A battery-type MCF rubber is considered as the case of having large induced electric current in a piezo-typed MCF rubber and as a soft polymer battery.

Table A1. Three types of electrolytically polymerized MCF rubber mainly divided by kinds of dopant [14].

\begin{tabular}{|c|c|c|c|c|}
\hline MCF Rubber Type & Induced Voltage & Induced Electric Current & Electric Resistance & Dopant \\
\hline Conductive type & $\begin{array}{c}\text { Minimum } \\
\text { (1-ordered mV) }\end{array}$ & $\begin{array}{c}\text { Minimum } \\
\text { (1-ordered } \mu \mathrm{A})\end{array}$ & $\begin{array}{c}\text { Minimum } \\
(0.1,1 \text {-ordered } \Omega)\end{array}$ & $\begin{array}{c}\text { KI, } \mathrm{I}_{2} \\
\text { Tetraethylammonium } \\
\text { tetrafluoroborate }\end{array}$ \\
\hline Piezo type & $\begin{array}{c}\text { Large } \\
(10,100 \text {-ordered } \mathrm{mV})\end{array}$ & $\begin{array}{c}\text { Small } \\
\text { (10-ordered } \mu \mathrm{A})\end{array}$ & $\begin{array}{c}\text { Large } \\
(\mathrm{k} \Omega, \mathrm{M} \Omega)\end{array}$ & $\begin{array}{c}\mathrm{TiO}_{2}, \mathrm{ZnO}, \mathrm{BaTiO}, \\
\text { Aluminum nitride, } \\
\text { Lead(II) titanium(IV) trioxide, } \\
\text { Potassium niobate, } \\
\text { Lithium niobate }\end{array}$ \\
\hline Battery type & $\begin{array}{c}\text { Large } \\
(10,100 \text {-ordered } \mathrm{mV})\end{array}$ & $\begin{array}{c}\text { Large } \\
(100 \text {-ordered } \mu \mathrm{A})\end{array}$ & $\begin{array}{c}\text { Large } \\
(\mathrm{k} \Omega, \mathrm{M} \Omega)\end{array}$ & $\begin{array}{l}\mathrm{KOH}, \\
\text { Lithium hydroxide monohydrate, } \\
\text { Trilithium Citrate Tetrahydrate }\end{array}$ \\
\hline
\end{tabular}




\section{References}

1. Kawasaki, H.; Komatsu, T.; Uchiyama, K. Dexterous anthropomorphic robot hand with distributed tactile sensors: Gifu hand II. IEEE/ASME Trans. Mechatron. 2002, 7, 296-303. [CrossRef]

2. Lee, H.K.; Chang, S.I.; Yoon, E. Dual-mode capacitive proximity sensor for robot application: Implementation of tactile and proximity sensing capability on a single polymer platform using shared electrodes. IEEE Sens. J. 2009, 9, 1748-1755. [CrossRef]

3. Kimoto, A.; Sugitani, N.; Fujisaki, S. A multifunctional tactile sensor based on PVD films for identification of materials. IEEE Sens. J. 2010, 10, 1508-1513. [CrossRef]

4. Yoshida, T. The Leading Edge of Development of Super Five Senses Sensor, 1st ed.; NTS Press: Tokyo, Japan, 2005; pp. 253-393.

5. Hammock, M.L.; Chortos, A.; Tee, B.C.K.; Tok, J.B.H.; Bao, Z. 25th anniversary article: The evolution of electronic skin (E-Skin): A brief history, design considerations, and recent progress. Adv. Mater. 2013, 25, 5997-6038. [CrossRef]

6. Shimada, K. Elastic MCF rubber with photovoltaics and sensing for use as artificial or hybrid skin (H-Skin): 1st report on dry-type solar cell rubber with piezoelectricity for compressive sensing. Sensors 2018, 18, 1841. [CrossRef]

7. Shimada, K. Elastic MCF rubber with photovoltaics and sensing on hybrid skin (H-Skin) for artificial skin by utilizing natural rubber: 2nd report on effect of tension and compression on properties of hybrid photo- and piezo-electricity in wet-type solar cell rubber. Sensors 2018, 18, 1848. [CrossRef]

8. Shimada, K. MCF rubber with photovoltaics and sensing for use as artificial or hybrid skin (H-Skin): Third report on electric charge and storage under tension and compression. Sensors 2018, 18, 1853. [CrossRef]

9. Shimada, K.; Saga, N. Mechanical enhancement of sensitivity in natural rubber using electrolytic polymerization aided by a magnetic field and MCF for application in haptic sensors. Sensors 2016, 16, 1521. [CrossRef]

10. Shimada, K.; Saga, N. Detailed mechanism and engineering applicability of electrolytic polymerization aided by a magnetic field in natural rubber by mechanical approach for sensing (Part 1): The effect of experimental conditions on electrolytic polymerization. World J. Mech. 2016, 6, 357-378. [CrossRef]

11. Shimada, K.; Saga, N. Detailed mechanism and engineering applicability of electrolytic polymerization aided by a magnetic field in natural rubber by mechanical approach for sensing (Part 2): Other and intrinsic effects on MCF rubber property. World J. Mech. 2016, 6, 379-395. [CrossRef]

12. Shimada, K. Enhancement of MCF rubber utilizing electric and magnetic fields, and clarification of electrolytic polymerization. Sensors 2017, 17, 767. [CrossRef] [PubMed]

13. Shimada, K.; Shuchi, S.; Kanno, H.; Wu, Y.; Kamiyama, S. Magnetic cluster and its applications. J. Magn. Magn. Mater. 2005, 289, 9-12. [CrossRef]

14. Shimada, K.; Kikura, H.; Takahashi, H.; Ikeda, R. Novel adhesion technique using metallic or non-metallic hydrous oxide of metal complexes involving magnetic compound fluid rubber under electrolytic polymerization and magnetic field for producing sensors. Sensors 2019, 19, 689. [CrossRef] [PubMed]

15. Shimada, K.; Ikeda, R.; Takahashi, H.; Kikura, H. Development of a magnetic compound fluid rubber stability sensor and a novel production technique via combination of natural, chloroprene and silicone rubbers. Sensors 2019, 189, 3901. [CrossRef] [PubMed]

16. Shokr, F.S. Electrical properties of conductive rubber blends subjected to solvent penetration. Plas. Rub. Compos. 2012, 41, 441-448. [CrossRef]

17. Ma, L.F.; Bao, R.Y.; Dou, R.; Zheng, S.D.; Liu, Z.Y.; Zhang, R.Y.; Yang, M.B.; Yang, W. Conductive thermoplastic vulcanizates (TPVs) based on polypropylene (PP)/ethylene-propylene-diene rubber (EPDM) blend: From strainsensor to highly stretchable conductor. Compos. Sci. Tech. 2016, 128, 176-184. [CrossRef]

18. Balasoiu, M.; Lebedev, V.T.; Orlova, D.N.; Bica, I. Magnetic field and particle concentration competitive effects on ferrofluid based silicone elastomer microstructure. Nanomat. Ceram. 2011, 56, 1177-1180. [CrossRef]

19. Lefevre, V.; Danas, K.; Pamies, O.L. A general result for the magnetoelastic response of isotropic suspensions of iron and ferrofluid particles in rubber, with applications to spherical and cylindrical specimens. J. Mech. Phys. Solids 2017, 107, 343-364. [CrossRef]

20. Yoshimura, K.; Nakano, K.; Hishikawa, Y. Flexible tactile sensor materials based on carbon microcoil/silicone-rubber porous composites. Compos. Sci. Tech. 2016, 123, 214. [CrossRef] 
21. Franesqui, M.A.; Yepes, J.; García-González, C.; Gallego, J. Sustainable low-temperature asphalt mixtures with marginal porousvolcanic aggregates and crumb rubber modified bitumen. J. Clean. Prod. 2019, $207,44$. [CrossRef]

22. Kawano, A.; Yamamoto, K.; Kadokawa, J. Preparation of self-assembled chitin nanofiber-natural rubber composite sheets and porous materials. Biomolecules 2017, 7, 47. [CrossRef] [PubMed]

23. Hassan, H.K.; Oraimi, S.A.; Taha, R.T. Evaluation of open-graded friction course mixtures containing cellulose fibers and styrene butadiene rubber polymer. J. Mat. Civil Eng. 2005, 17, 416. [CrossRef]

24. Shimada, K.; Ikeda, R.; Kikura, H.; Takahashi, H. Enhancement of diversity in production and application utilizing electrolytically polymerized rubber sensors with MCF: 2nd report on various engineering applications. Sensors 2020. to be submitted.

25. Shimada, K.; Saga, N. Development of a hybrid piezo natural rubber piezoelectricity and piezoresistivity sensor with magnetic clusters made by electric and magnetic field assistance and filling with magnetic compound fluid. Sensors 2017, 17, 1521. [CrossRef]

26. Toko, K.; Hara, D.; Tahara, Y.; Yasduura, M.; Ikezaki, H. Relationship between the amount of bitter substances adsorbed onto lipid/polymer membrane and the electric response of taste sensors. Sensors 2014, 14, 16274. [CrossRef]

(C) 2020 by the authors. Licensee MDPI, Basel, Switzerland. This article is an open access article distributed under the terms and conditions of the Creative Commons Attribution (CC BY) license (http://creativecommons.org/licenses/by/4.0/). 